\title{
LA CONFORMACIÓN DE LA PROVINCIA JESUÍTICA DE TOLEDO EN TORNO AL GENERALATO DE DIEGO LAÍNEZ (1556-1565)*
}

\author{
POR \\ DAVID MARTÍN LÓPEZ \\ Y \\ FRANCISCO JOSÉ ARANDA PÉREZ \\ Universidad de Castilla-La Mancha (España)
}

\section{RESUMEN}

La novísima Compañía de Jesús empezó pronto a incardinarse en el territorio ibérico, patria de su fundador. Como uno de los territorios más importantes de la Cristiandad católica, pronto se vio la necesidad de distribuir lo que pronto sería una gran corona en una serie de provincias para unos más eficaces gobierno y evangelización. Después de una primera división, en la época del generalato del español Laínez se pusieron las bases de la pentaprovincialización definitiva entre Portugal, Castilla, Aragón, Bética y —la novedad-Toledo.

\section{PALABRAS CLAVE}

Compañía de Jesús; Provincia de Toledo; Diego Laínez; $2^{\circ}$ Generalato; Castilla; España; Felipe II; Órdenes Religiosas.

* Artículo inserto en el Proyecto Nacional de Investigación "Monarquía Universal, Hispánica o Católica. Una revisión de la cultura política de las elites hispánicas en los reinados de Felipe III y Felipe IV (2)" (MUHICA2), financiado por la Dirección General de Investigación del Ministerio de Ciencia e Innovación-Ministerio de Economía y Competitividad (referencia HAR2009-08765-HIST). 


\section{THE FORMATION OF THE JESUIT PROVINCE OF TOLEDO DURING THE GENERALATE OF LAÍNEZ (1556-1565)}

\section{ABSTRACT}

The newest Jesuits soon began incardinated in the Iberian territory, home of its founder. As one of the most important territories of Catholic Christianity, soon saw the need to distribute what would soon become a large crown in a number of provinces for a more effective government and evangelization. After the first division, at the time of the Spanish general Lines were the final foundations of penta-provincialization between Portugal, Castile, Aragon, Andalusia and —novelty— Toledo.

\section{KEY WORDS}

Society of Jesus; Province of Toledo; Diego Laínez; $2^{\text {nd }}$ Generalate; Castile; Spain; Philippe the $2^{\text {nd }}$; Religious Orders.

$\begin{array}{ll}\text { Recibido/Received } & 10-12-2013 \\ \text { Aceptado/Accepted } & 24-02-2014\end{array}$

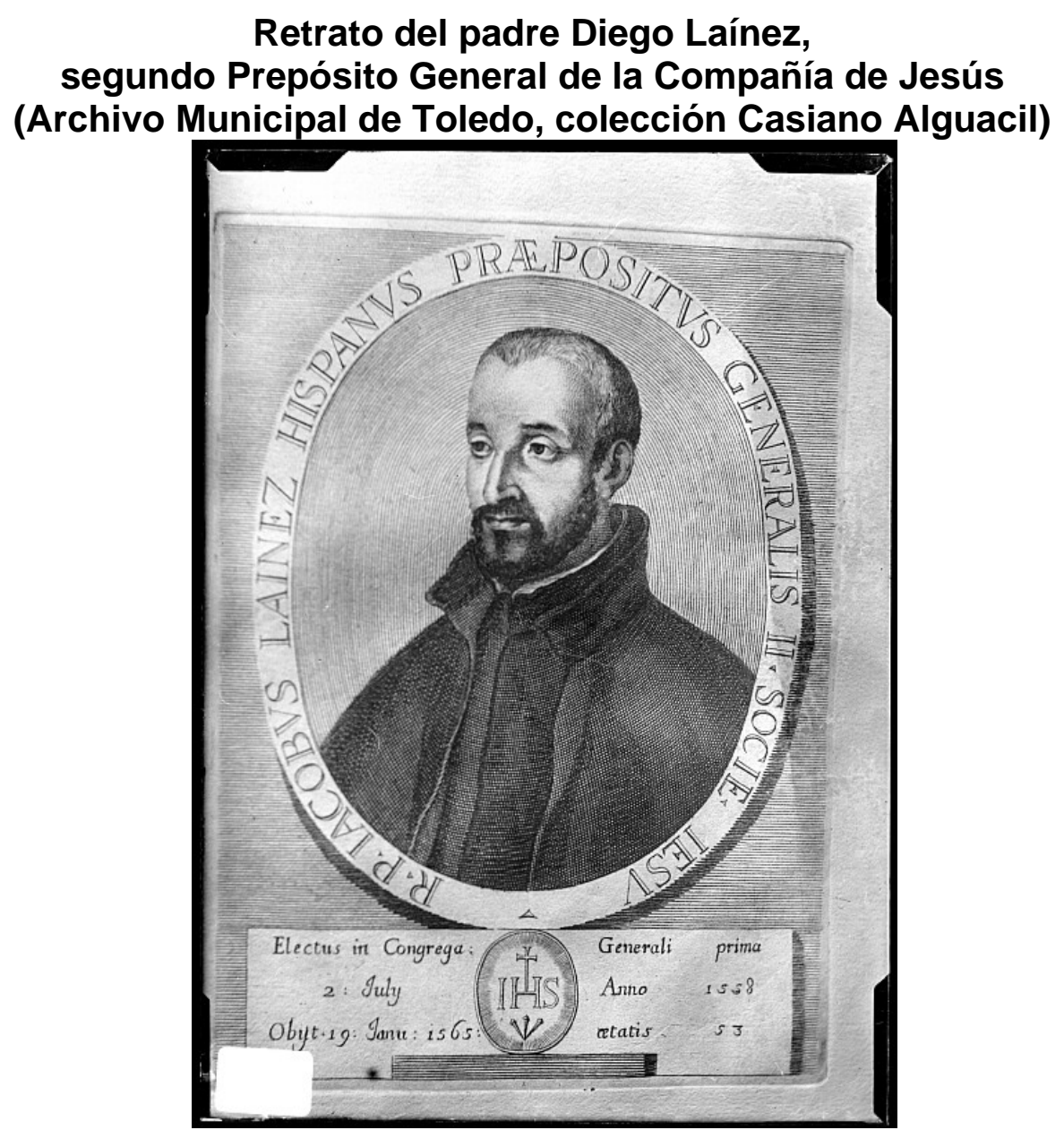


Los jesuitas instauraron una eficaz estructura jerárquica y de gobierno en su orden, lo cual, muy pronto, y máxime con el paso del tiempo, constituyó una de sus señas de identidad y un rasgo que puso de manifiesto su modernidad respecto a otras órdenes religiosas de origen medieval. No obstante, este carácter distintivo e innovador se convirtió también en arma arrojadiza por parte de sus detractores, que veían exagerada la complejidad organizativa jesuita, viéndola casi más propia de un Estado civil-monárquico que de menesterosos y humildes religiosos. Esto, unido a la estrecha vinculación que constitucionalmente establecieron con la Santa Sede Romana, suscitó referirse a ella como una especie de pérfido "Estado dentro de un Estado", como una quasi monarquía universal subordinada al Papa, con corte en Roma pero con excesiva extensión e influencia a nivel mundial. ${ }^{1}$ Este fue el argumento utilizado en los siglos posteriores y, sobre todo, en el XVIII para tachar a los jesuitas de anti-regalistas, anti-monárquicos $\mathrm{y}$, por consiguiente, de actuar en contra de la misma patria. ${ }^{2}$

Esta estructura tan "política" a la que nos estamos refiriendo constaba, en resumidas cuentas, de un Superior, denominado Prepósito General, que tenía su sede en Roma y que al morir era sustituido por un Vicario, mientras que las máximas facultades de decisión de la Compañía recaían en la Congregación General, formada por los profesos, que se reunía para elegir a su sucesor $\mathrm{o}$, en casos extraordinarios, para realizar algunas modificaciones en el Instituto jesuita. Por debajo se encontraban los Asistentes y, fundamentalmente, los Provinciales, que se encargaban de las "Provincias" y de las "Asistencias", un conjunto de provincias que se unían por afinidades culturales, históricas, lingüísticas. Por debajo de las circunscripciones provinciales, se encontraban, siempre en orden descendente, la Casa Profesa, los Colegios y los Noviciados. Por último, como (enorme) extensión

${ }^{1} \mathrm{~B}$ (iblioteca) N(acional de) E(spaña) (en adelante BNE): Mss/418: Instruttione a Prencipi del modo col quale si governano li Padri Gesuiti, fols. 259r-260v.

2 Ibidem, 261r-262v. En la misma línea se expresaba Ayguals de Izco al citar las palabras del Señor de Fresne en 1606: "Muchos venecianos y otros italianos, después de muchos años, se han retirado y aseguran haber reconocido que dicho general no tiene de religioso más que el traje, y que dirige todas sus acciones como un hombre que está fundando un grande imperio; que sólo a fuerza de oro se logran sus favores y que, sin comparación, hace más caso de los que saben traer el agua al molino, que de la doctrina y la piedad". Ayguals de Izco, D.W. 1848. Los jesuitas o análisis documentado de la Compañía de Jesús por las autoridades más competentes desde su fundación en el año 1540: I, 167 Madrid. Por otra parte, muchos de estos argumentos son los que se deslizaron cuando se aplicó el dictamen fiscal de Campomanes para su extrañamiento de España. Rodríguez de Campomanes, V. P. 1977. Dictamen fiscal de expulsión de los jesuitas de España (1766-1767) Madrid: edición y estudio de J. Cejudo y T. Egido. 
de todo se encontraban los territorios de misión, aquellos lugares en los que la Compañía había llegado, pero no se había producido un establecimiento consolidado con una edificación estable. Desde luego que esta organización se fue desarrollando y evolucionando con el paso del tiempo, tal y como veremos en las siguientes páginas, mostrándose como una de las principales potencialidades esta capacidad de adaptación a tantas circunstancias cambiantes de espacio, cultura y tiempo. Sabido es que las continuas reformas que vivió la Compañía de Jesús en sus primeros años de existencia permitieron a los jesuitas instalarse en territorios y civilizaciones tan variopintos y diversos como los extremo-orientales, los centro-este europeos, los africanos y los iberoamericanos. Hasta las alturas del generalato de Claudio Acquaviva (1580-1615, cuarto en orden) no comenzaron a normativizarse determinados aspectos de la Compañía, siendo la Ratio Studiorum el principal ejemplo de ello, puesto que, hasta entonces, el único corpus preceptivo de la Orden fueron las Constituciones que Ignacio de Loyola en persona había redactado a principios de la década de 1550. Pero para que esa regulación se produjera, antes fueron necesarias varias modificaciones previas. En el caso que nos ocupa aquí, las fronteras provinciales no se delimitaron firmemente, y en más de una ocasión podemos ver cómo se planteó a Roma o al asistente español que una determinada zona o colegio "emigrara" de provincia. A pesar de que dé la impresión de que la configuración provincial de 1562 permaneció intocable hasta la traumática expulsión de 1767, hubo algunos intentos entre medias de modificación o alteración. Así, por ejemplo, en 1597 se plantearon diversos cambios que pasaban por la creación de una nueva provincia, pero que no llegaron a fraguar, como vemos en este comentario epistolar:

"A la de Castilla podrá pertenecer el obispado de Pamplona, Calahorra, Osma, Burgos, Palencia, Segovia, Astorga; y así le quedarían los colegios de Pamplona, Logroño, Soria, Oñate, Vitoria (que dicen que está a punto), Burgos, Villímar, Palencia, Valladolid, Arévalo, Segovia, con la casa profesa de Valladolid y casa de probación de Villagarcía; y todavía aquí hay donde recibir y también se podrían valer de Salamanca, pues está cerca.

La otra provincia había de tener el arzobispado de Santiago con los obispados de Galicia y Asturias, Salamanca, Ávila, Ciudad Rodrigo, Plasencia, Coria, Badajoz; y así tendría los colegios de Santiago, Monterrey, Monforte, Oviedo, León, Salamanca, Ávila, Plasencia, con la casa de probación y colegio de Medina del Campo, y mucha tierra, en que se poder extender, aun más que queda la de Toledo". 3

${ }^{3}$ A(rchivum) R(omanum) S(ocietate) I(esu) (en adelante ARSI), Toletana-37a: "Carta de Antonio Ramiro, 3 de noviembre de 1597". 
Junto con esta estructura geográfica, la singularidad de la organización jesuita también se encontraba en las distintas categorías que se establecían entre los religiosos en función de los votos que hubieran profesado y de las labores que desempeñaban. Los jesuitas no se dividían entre hermanos legos y profesos, como la mayoría de las órdenes religiosas, sino que instauraron una clasificación compuesta por tres categorías: los profesos, que habían hecho los cuatro votos; coadjutores espirituales, que con los tres votos de rigor habían sido ordenados sacerdotes; y los coadjutores temporales, que no habían profesado votos y que se ocupaban de las labores subalternas en las casas y colegios. A estos hay que incluir, lógicamente, a los novicios, de la misma forma que el resto de los institutos religiosos de vida consagrada.

\section{Mapa 1. Las provincias jesuíticas en la Península Ibérica, 1554 (división primera)}

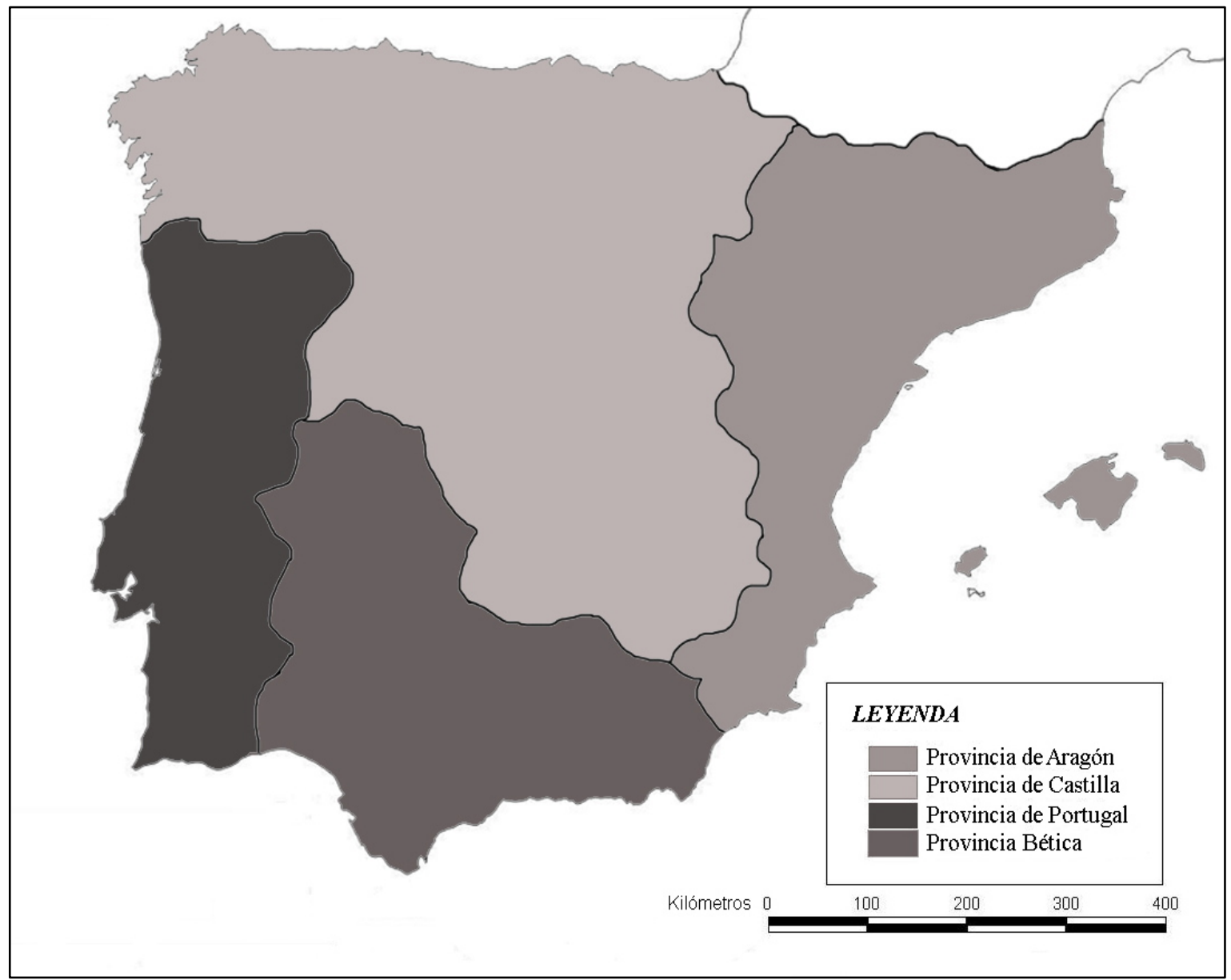

El desarrollo y la evolución de las circunscripciones territoriales jesuíticas en la Península Ibérica marchan en consonancia con el aumento de fundaciones y de las localidades en las que la Compañía se hacía presente, 
aunque no hubiera todavía un establecimiento sólido. De este modo, a lo largo de la década de 1540 y en los primeros años de la de 1550 se erigieron tal número de centros jesuitas que desde Roma se vio necesaria la división del hasta ahora entero territorio-provincia ibérico-hispánico para poder gestionar mejor las nuevas fundaciones $y$, por supuesto, pensando en la necesaria organización de la ingente correspondencia que se intercambiaba de manera asidua entre Roma y España. En efecto, en enero de 1554, el padre Polanco, secretario personal de Ignacio de Loyola, escribía a los padres Araoz y Nadal para que se llevase a cabo esa distribución en provincias de los territorios españoles, con la siguiente y clara instrucción:

"Dividir España en tres provincias, id est, Castilla [la] Vieja y el reino de Toledo por una; el Andalucía, Granada y lo que en Extremadura se prepara, por otra; y lo que hay en Aragón, Cataluña y Valencia, por otra; y lo de Portugal, por la cuarta".

Para cuando se produjo esta división, los jesuitas estaban enclavados en los municipios de Alcalá de Henares (1543-1546), Barcelona (1545), Gandía (1546), Salamanca (1548), Burgos, Valladolid, Medina de Pomar, Castro Urdiales, Portugalete, Laredo y Medina del Campo (1551), Córdoba (1552), Ávila, Plasencia, Granada, Sevilla y el noviciado de Simancas (1554). Esta nómina de localizaciones jesuitas se puede ampliar si tenemos en cuenta otros lugares en los que las gestiones para el establecimiento se encontraban en esos momentos en pleno proceso de negociaciones, por lo que su instalación tendría que esperar aún unos años más. En esta misma situación nos encontramos con varias de las fundaciones de la provincia que nos va a ocupar, como son Murcia, Cuenca, Belmonte, Toledo, Ocaña, Madrid y Oropesa. El primer caso, además, tiene el detalle curioso de que se fundó perteneciendo a la provincia aragonesa, para, posteriormente terminar incluida en la de Castilla por presiones de su fundador, el obispo Esteban de Almeyda. La fundación conquense puso sus cimientos en 1554, cuando el clérigo Pedro del Pozo les cedió unas casas para que sirvieran de residencia a jesuitas venidos de Alcalá de Henares, pero las negociaciones con el fundador, el también canónigo Pedro de Marquina, para instalar un colegio se extendieron hasta 1561. La de Belmonte se retrasó hasta 1558 por los pactos que los jesuitas mantuvieron con los sucesores del marqués de Villena, que murió en 1556 dejando una dotación para la erección de un colegio de la

4 "Carta de Juan Alfonso de Polanco a Antonio de Araoz, de Roma a 1 de enero de 1554", en Monumenta Ignatiana ex autographis vel ex antiquioribus exemplis collecta, 1903: VI, 128. Madrid. Del mismo modo se expresaba en la carta a Jerónimo Nadal del 7 de enero de 1554, con la salvedad de que en ese caso deja al parecer del que, años más tarde llegara a comisario, la inclusión de la zona salmantina en la provincia andaluza. Monumenta Ignatiana: VI 151-152. Hay que recordar que la provincia portuguesa ya existía desde 1546. 
Compañía, por lo que entendemos que los religiosos se habrían dado a conocer en la zona antes de esa fecha. Las de Toledo y Ocaña se retrasaron hasta ese mismo año por las trabas que puso el adusto arzobispo toledano, don Juan Martínez Silíceo, pero la Compañía ya habría iniciado sus contactos toledanos entre los años 1547 y 1549. El establecimiento madrileño comenzaría a fraguarse en torno a 1556, aunque hasta 1560, al filo del traslado de la Corte allí, no conseguirían una casa estable. Por su parte, la inclusión de la fundación de Oropesa en estos años puede resultar sorprendente si atendemos a que los esfuerzos de Fernando Álvarez de Toledo, conde de Oropesa, y de su hermano, Francisco de Toledo, famoso virrey del Perú, fructificaron en la década de 1570 y, de manera más firme, en la de 1580. Pero eso no es óbice para que los contactos se iniciaran bastantes años antes y que los detalles de la dotación y las circunstancias de entonces de la propia Compañía durante el generalato posterior de Francisco Borja retrasaran la fundación.

Tras la muerte de Ignacio de Loyola en 1556, Diego Laínez fue elegido prepósito general en $1558,{ }^{5}$ iniciándose un generalato próspero en fundaciones en las provincias españolas: a las ya mencionadas de Toledo, Ocaña, Madrid, Cuenca y Belmonte se añadieron el colegio de Montilla y la residencia de Jesús del Monte (1558), Segovia, Logroño y Palencia (1559), Villímar y Villar de la Vega (1560), Mallorca (1561), Trigueros (1562) y Cádiz (1564). Además, en la provincia toledana, que se crearía durante este generalato, siguieron los contactos con los benefactores de Oropesa y se iniciaron otros con don Juan Pacheco de Silva y doña Jerónima de Zúñiga y Mendoza, fundadores del colegio de Villarejo de Fuentes, que después fue noviciado de la provincia. Buena parte de estas fundaciones se produjeron de la mano de personajes tan importantes como los comisarios Francisco de Borja y Jerónimo Nadal, y de otros como Bartolomé de Bustamante, que intervinieron de manera activa en casi todos los casos, negociando hábilmente con los benefactores y realizando labores de enlace con el general romano. Las personalidades de los comisarios han sido objeto de varios estudios y publicaciones a lo largo de los años, ${ }^{6}$ razón por la cual no es

${ }^{5}$ La elección del sustituto del Fundador de la Orden se retrasó por los problemas existentes en Europa en esos años. El papa Paulo IV había declarado la guerra a Felipe II con la ayuda del rey Francisco I de Francia. Ante esta situación, el monarca español cerró las fronteras españolas e impidió que nadie saliera de ellas sin permiso. El conflicto continuó hasta 1557, con la victoria de Felipe II en la batalla de San Quintín y se cerró con el tratado de Cateâu-Cambrésis. Pero el bloqueo no concluiría hasta fines de 1557, retrasándose la elección hasta el año siguiente.

6 Sobre Francisco de Borja, véase: García Hernán, E. 1999. Francisco de Borja, Grande de España Valencia; García Hernán, E. 2000. La acción diplomática de Francisco de Borja al servicio del Pontificado, 1571-1572 Valencia; García Hernán, E. y Ryan, M. P. (eds.) 2011. Francisco de Borja y su tiempo. Política, 
preciso detenerse ahora en ellos. Sin embargo, creemos conveniente fijarnos un momento en la figura de Bustamante, cuyo ministerio político y espiritual en la Compañía de Jesús ha pasado un tanto desapercibido, al menos todo aquello que se encuentra al margen de sus valiosos conocimientos en el arte arquitectónico.

Bartolomé de Bustamante se había formado intelectualmente en la Universidad de Alcalá, en la que había cursado estudios de Teología, Artes y Cánones, aunque desconocemos qué graduación alcanzó en ellos. Durante buena parte de su vida estuvo vinculado al cardenal Juan Ares Pardo de Tavera, primero como secretario de cámara en el Consejo de Castilla entre los años 1524 y 1539 y luego ocupando el mismo cargo en la archidiócesis de Toledo hasta 1545, año de la muerte del cardenal. En ese tiempo desempeñó labores de representación del arzobispo-cardenal ante el emperador Carlos $\mathrm{V}$ y el papa Paulo III (1529-30), aunque lo que más recuerdo dejó fueron algunas sonadas intervenciones arquitectónicas, como las trazas y la elección del emplazamiento del Hospital de San Juan Bautista, el proyecto de la portada del palazio arzobispal en Toledo y las reformas del palacio de los arzobispos en Alcalá (1554). ${ }^{7}$ Fue nombrado administrador de las obras del Hospital de San Juan Bautista, hasta su entrada en la Compañía de Jesús en 1552. Según indican los historiadores jesuitas, el ingreso se produjo al contemplar la bondad de ánimos que estos religiosos mostraban ante la beligerancia del comportamiento que el cardenal Silíceo tuvo con ellos.

Ya como jesuita, participó en varias fundaciones a lo largo de la geografía jesuítica española, en las que, además, intervino en la erección de sus edificios, por mor de sus conocimientos en edificación. Se implicó de una manera o de otra en los colegios de Murcia, Villarejo de Fuentes, Caravaca, Granada, Trigueros, Cádiz, Segura de la Sierra, la casa profesa de Sevilla y el

religión y cultura en la Edad Moderna. Valencia-Roma; Ribadeneyra, P. de. 1594. Vida del P. Francisco de Borja en Madrid, por Pedro Madrigal; Santalla, F. 1681. El grande a lo divino S. Francisco de Borja..., s.l., s.n.; y los 7 volúmenes editados del Monumenta Borgia. Sobre Jerónimo Nadal, véase: Nadal Cañellas, J. 2007. Jerónimo Nadal. Vida e influjo Bilbao; Lop Sebastiá. M. (ed.) 2011. Las pláticas del P. Jerónimo Nadal Bilbao; Nadal, J. 1593. Evangelicae Historiae Imagines: Ex ordine Euangeliorum, quae toto anno in Missae Sacrificio recitantur, In ordinem temporis vitae Christi digestae Amberes; Nadal, J. 1594. Adnotationes et Meditationes in Evangelia: Quae in sacrosancto missae sacrificio toto anno leguntur, cum evangeliorum concordantia, historiae integritati sufficienti Amberes, Martinus Nutius; y los 4 volúmenes editados del Monumenta Nadal.

7 Sobre esta labor artística véase Marías, F. 1983-1986. La arquitectura del Renacimiento en Toledo, 1541-1631 Toledo. Véase también, del mismo autor: Marías, F. 2007. El Hospital de Tavera de Toledo Sevilla. 
noviciado de Simancas (1586-1605). ${ }^{8}$ Es comprensible que el profesor Rodríguez G. de Ceballos le viera como el iniciador de la arquitectura jesuítica en España si tenemos en cuenta las indicaciones que realizó en estos años para que las fábricas colegiales se realizaran en una determinada línea, promoviendo el uso y aprovechamiento de los recursos que se tuvieran, frente a los excesos o caprichos que muchos benefactores pretendían con construcciones que iban más allá de lo que sus dotaciones podían permitir. Como se puede ver en la correspondencia, esta diferencia de concepto, este realismo de Bustamante, provocó más de un enfrentamiento. Otro detalle destacable de sus intervenciones es que en ellas se ha podido observar un principio de la homogeneización constructiva que buscaron los jesuitas en los años siguientes, inclusive el control desde Roma de las trazas que se seguirían en los distintos edificios que se fueran erigiendo. Pero no pasemos por alto que Bustamante no fue solamente el primer arquitecto de la Compañía española, sino que también ocupó diversos cargos de gobierno, como los de Visitador de las provincias andaluza y toledana en $1566 .^{9}$

Todas las fundaciones a las que hemos hecho referencia unas líneas más arriba propiciaron que entre los años 1561 y 1562 se decidiera crear una nueva provincia en los territorios españoles, que ocupara la estratégica franja central de la península y que estuviera compuesta fundamentalmente por territorios que anteriormente pertenecían a las provincias andaluza, castellana y aragonesa. Esta división se realizó, concretamente, durante la visita que desarrolló Jerónimo Nadal en las provincias españolas durante esos dos años. $^{10}$ La nueva provincia obtuvo un carácter oficial poco tiempo después, durante la $\|^{\mathrm{a}}$ Congregación General, convocada tras la muerte de Diego Laínez en 1565. En esta Congregación no sólo se consolidaba el nuevo mapa jesuítico de las provincias españolas, sino que también se afirmaba la estructura de gobierno jesuita con la instauración del cargo de Provincial y una serie de normas relacionadas con el mismo. En este paso hacia adelante en el desarrollo de la estructura y de los órganos de gobierno de la Orden, se estableció una temporalidad trianual al cargo y se le concedió un mayor poder de decisión en todos los asuntos relacionados con su circunscripción. Esta traza estuvo íntimamente relacionada con la eliminación de la figura del Comisario y la aparición del Asistente, que era el intermediario jerárquico entre las provincias y la Curia romana, pero que no tenía tanta relevancia como aquel. ${ }^{11}$ Esta afirmación del gobierno provincial se amplió con el

8 Pereda de la Reguera, M. 1950. Bartolomé de Bustamante: 86-105. Santander; Rodríguez Gutiérrez de Ceballos, A. 1967. Bartolomé de Bustamante y los orígenes de la arquitectura jesuítica en España: 81, 97, 229. Roma.

${ }_{9}$ Pereda de la Reguera, M. 1950: 102.

${ }^{10}$ M(onumenta) (en adelante M) Nadal II: 85; MNadal IV: 737-751.

11 Ser Pérez, F. del. 1998. "La provincia jesuítica de Castilla en el Archivum Romanum Societatis lesu". Cuadernos de Historia Moderna 20: 7. 
establecimiento de las Congregaciones Provinciales, en las que se reunían cada tres años los padres profesos de cada provincia. En ellas se elegían los denominados Procuradores, que eran enviados a Roma en compañía del Provincial ${ }^{12}$ para la Congregación de Procuradores, ${ }^{13}$ en la que se informaba al General de la situación de sus territorios y se le transmitía una serie de peticiones. ${ }^{14}$ Otra decisión importante que se tomó en aquella Congregación fue el establecimiento de una Casa Profesa en cada provincia, que actuase como lugar de recogimiento de los padres profesos y centro espiritual de la provincia. Su instalación en Toledo, que, al igual que ocurría en el caso de la provincia, se había realizado en torno a 1562, nos ayuda a entender que fundamentalmente desde allí se organizaran diversas misiones en los años posteriores hacia el Sur y el Oeste de la provincia con el objetivo de darse a conocer en los ámbitos rurales más alejados e incluso para evangelizar y sacar al pueblo de sus posibles errores religioso-teológicos.

\section{Mapa 2. Las provincias jesuíticas en la Península Ibérica, 1562 (división segunda)}

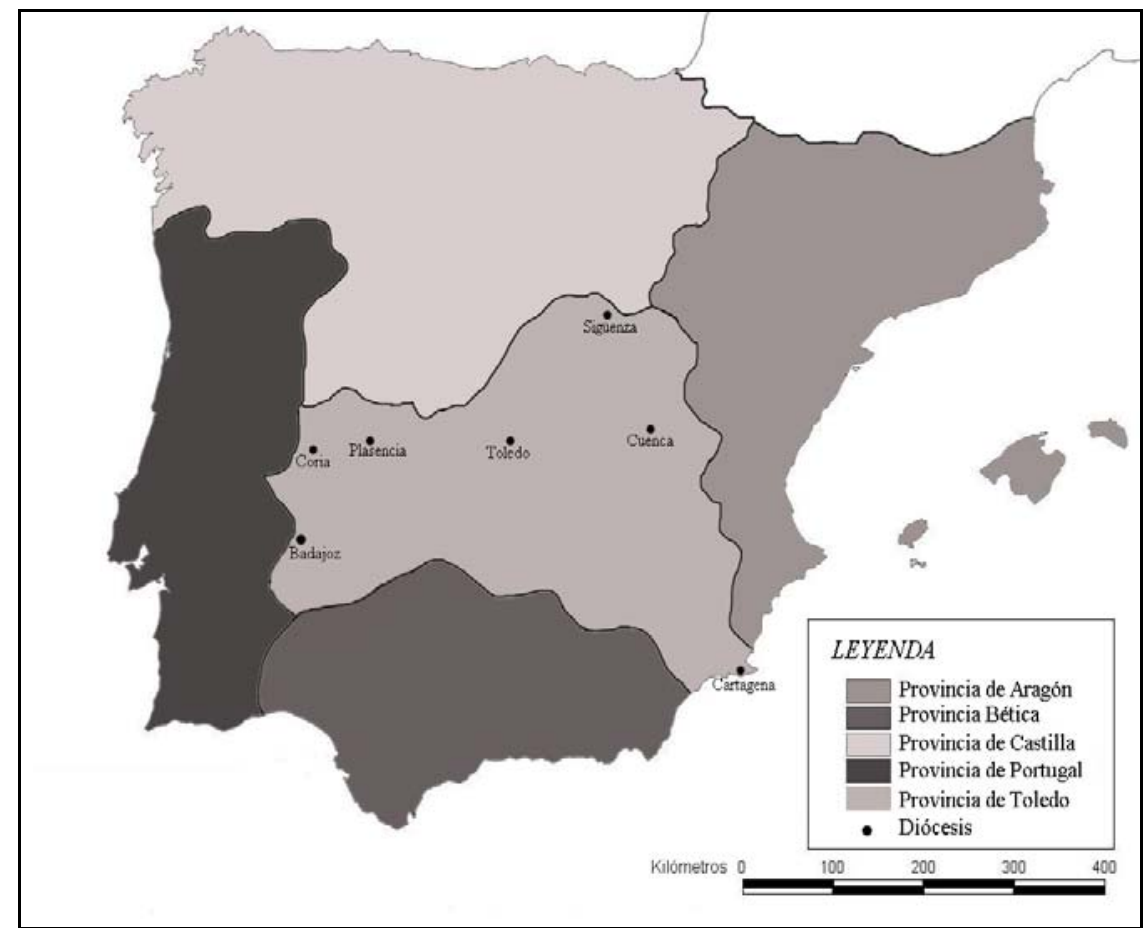

${ }^{12}$ Astrain, A. 1902-1925. Historia de la Compañía de Jesús en la Asistencia de España: II, 216. Madrid.

13 Institutum S. J., Congregatio II, Dec. 19, p. elect.

${ }^{14}$ Esto es, las actas provinciales, con las propuestas generales y personales de cada territorio, y las respuestas emitidas desde Roma, que pueden consultarse en el ARSI, sección "Congregationes", a partir de la signatura/volumen 41. 
Con todo, vamos a centrarnos en la conformación de esta nueva provincia toledana, principal objetivo del presente estudio.

\section{EL EJE FUNDAMENTAL ALCALÁ-TOLEDO}

Indudablemente, la extensión de la Compañía de Jesús por la submeseta sur se desarrolló a través de la irradiación de religiosos desde dos puntos clave: Alcalá de Henares y Toledo. La ciudad complutense, tan celebrada por la magnífica universidad fundada a principios del siglo XVI por el cardenal fray Francisco Jiménez de Cisneros, fue el primer asentamiento jesuítico que se produjo en dicha zona, amén de uno de los primeros de toda la Península Ibérica. ${ }^{15}$ No era de extrañar que éste fuera uno de los lugares en donde principiara la Compañía, puesto que dicha ciudad tuvo un lugar importante en el periplo personal de Ignacio de Loyola. Allí es donde comenzó su formación intelectual, hasta que las intempestivas acusaciones de alumbradismo ante la Inquisición le llevaron más allá de los Pirineros para continuar sus estudios en la prestigiosísima París. Esto, unido al espíritu humanista que se vivía en la ciudad (en estrecha relación con la universidad), permitió que los jesuitas no fueran observados con recelo a su llegada a otras localidades relacionadas, como fueron los casos acaecidos durante los años del pontificado del ya aludido don Juan Martínez Guijarro-Silíceo. Entre los años 1543 y 1546 se gestó el establecimiento con la ayuda del doctor don Alonso Ramírez de Vergara, un personaje fundamental para conocer el devenir de los "hermanos de San Ignacio" en sus primeros años de existencia y en su propagación por la zona, fundamentalmente en la parte cercana del obispado conquense, como veremos más adelante.

Teniendo Alcalá como primigenio núcleo jesuita en la zona, es lógico pensar que este centro estuviera en el germen del otro enclave organizador de la que será la nueva provincia. Según relatan Francisco Antonio y Bartolomé de Alcázar en sus historias de dicha provincia, varios toledanos marcharon en 1547 a Alcalá para realizar los Ejercicios Espirituales bajo la dirección de Francisco Villanueva, primer superior del colegio alcalaíno. ${ }^{16} \mathrm{De}$ los siete a los que hacen mención, son dignos de destacar tres: Juan Bautista de Segura, que ingresó en la Compañía en Alcalá en 1556, hizo profesión de votos en Salamanca, para terminar como vice-provincial en la misión de la

${ }^{15}$ Sobre el papel cultural e intelectual de Alcalá véase: Aranda Pérez, F. J. 2013. "El influjo complutense, de Cisneros y Fonseca a Carranza", en García Pinilla, I. J. (Coord.). Disidencia religiosa en Castilla la Nueva en el siglo XVI: 29-57. Toledo.

${ }^{16}$ Alcázar, B. de. 1710. Chrono-Historia de la Provincia de Toledo: I, 88 y 115116; II, 65-67. Madrid. Antonio, F. 1604. Historia de la Provincia de Toledo: I, 15-16; "Carta de Juan Alfonso de Polanco a Francisco Villanueva, de Roma a 25 de enero de 1549", en Monumenta Ignatiana: II, 326. 
Florida, donde murió en $1572 ;{ }^{17}$ Tomás de Soto era racionero de la parroquia de Santo Tomé, ingresó en 1558, profesó en 1572 y residió en la casa profesa toledana más de 35 años ininterrumpidos, ejercitándose allí como confesor, predicador, librero y síndico; ${ }^{18}$ y Bernal de Venegas, que perteneció al entorno del maestrescuela toledano Francisco Álvarez de Toledo, fundador del colegio universitario de Santa Catalina, ${ }^{19}$ del que Venegas fue rector en el año académico 1548-1549 y que, según Román de la Higuera, en algún momento de su vida se convertiría en jesuita, puesto que sitúa su muerte en el colegio de Montilla, en la provincia jesuítica de Andalucía. ${ }^{20}$ De este modo, ya tenemos jesuitas relacionados con el corazón del arzobispado de Toledo desde sus primeros años, lo cual no quiere decir que la relación con la Sede Primada siempre fuera cordial. De hecho, en ese mismo año en el que se sitúa ese viaje para realizar los Ejercicios Espirituales, en la Catedral se estaba aprobando, con gran controversia, un estatuto de limpieza de sangre, que pronto sería un verdadero obstáculo para que la Compañía de Jesús se expandiera por esta franja central de la península. ${ }^{21}$

${ }^{17}$ Nieremberg, J.E. 1644. Firmamento Religioso de lúcidos astros en algunos claros varones de la Compañía de Jesús: 705-706 en Madrid, por María de Quiñones; Nieremberg, J.E. 1666. Varones Ilustres en santidad, letras y celo de las almas de la Compañía de Jesús: 459-467 en Madrid, por loseph Fernández de Buendía; Alcázar, B. de. 1710: II, 334-337 y 444-445; BNE: Mss/12861: Monzón, B. de. 1658. Menologio de Ylustres por todo el orbe y famosos hijos de San Ygnazio Patriarca y fundador de la Compañía de Jesús en ciento y diez y ocho años de su fundación hasta el presente de 1658: I, 519-520.

18 Antonio, F. 1604: II, 330-350; Alcázar, B. de. 1710: VI, 418-427; Nieremberg, J.E. 1644: 27-31.

${ }^{19}$ Vaquero Serrano, M. C. 2006. El libro de los maestrescuelas. Cancelarios y patronos de la Universidad de Toledo en el siglo XVI Toledo; Martín López, D. 2013. Orígenes y evolución de la Universidad de Toledo (1485-1625), memoria inédita presentada en las Cortes de Castilla-La Mancha, Toledo.

${ }^{20} \mathrm{BNE}, \mathrm{Mss} / 1293:$ Jerónimo Román de la Higuera, Historia eclesiástica de la imperial ciudad de Toledo, fol. 217v.

${ }^{21}$ Para más información sobre los estatutos de limpieza de sangre y sus distintas implicaciones en la Edad Moderna, véase: Sicroff, A. A. 1985. Los estatutos de limpieza de sangre: controversias entre los siglos XV y XVII Madrid; más recientemente Hernández Franco, J. 2011. Sangre limpia, sangre española. El debate de los estatutos de limpieza (siglos XV-XVII) Madrid; Martínez Millán, J. 2009. "Nobleza hispana, nobleza cristiana: los estatutos de limpieza de sangre", en M. Rivero Rodríguez (coord.), Nobleza hispana, Nobleza cristiana: la Orden de San Juan: 677-758. Madrid; Aranda Pérez, F. J. 2009. “¿Sangre o mérito? Noblezas, virtudes cívicas, virtudes religiosas en la Monarquía Hispánica de los Felipes”, en M. Rivero Rodríguez (coord.), Nobleza hispana, Nobleza cristiana: la Orden de San Juan: 832-862. Madrid; Aranda Pérez, F. J., Martín López, D. 2012. "Pensamiento político more Societatis lesu: entre la teología moral y la razón de Estado", en J. Martínez Millán, H. Pizarro Llorente, E. Jiménez Pablo (Coords.), Los Jesuitas. Religión, política y educación (siglos XVI-XVIII): 1.309-1.338. Madrid. Sobre el caso 


\section{Mapa 3. La provincia jesuítica de Toledo}

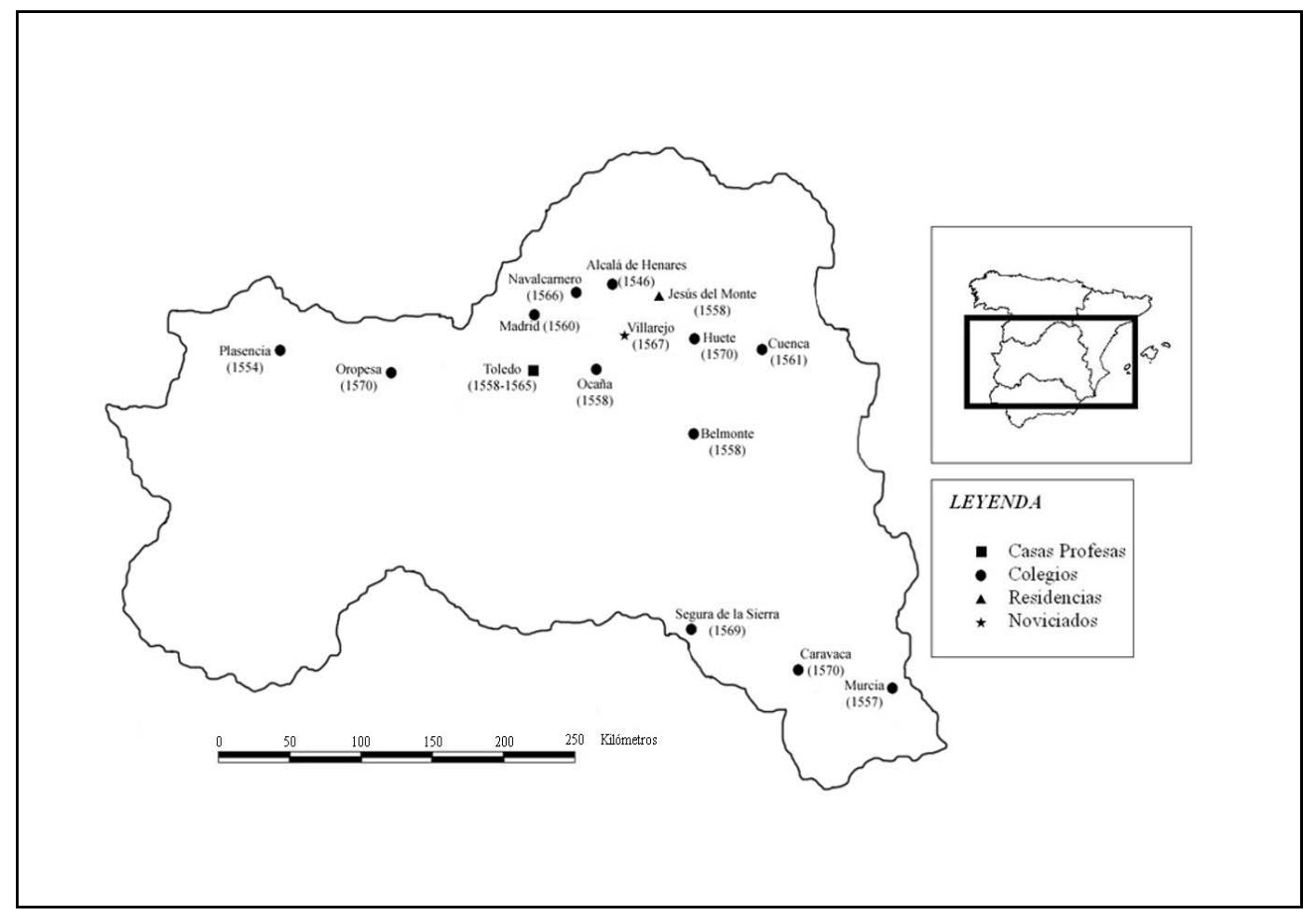

El enfrentamiento de los jesuitas con el duro arzobispo toledano Silíceo forzó una pausa de años en la expansión de la Orden por una gran parte del territorio; aunque no en su totalidad, puesto que en los obispados placentino y murciano-cartaginés hubo fundaciones, y en el conquense se iniciaron contactos. Los impedimentos que ponía Silíceo estaban basados en dos puntos bastante conocidos: por una parte, el enorme recelo que provocaba en él una orden religiosa en la que abundaban los candidatos conversos y que de entrada no contemplaba ni veía necesario establecer un estatuto de limpieza de sangre que impidiera el acceso a los cristianos nuevos; por otra parte, la desconfianza que generaba la aparición en su diócesis de unos religiosos que proclamaban su voto de obediencia directa al pontífice, lo cual era tenido como una intromisión romana en su gobierno episcopal. El exceso de celo religioso - temía que su diócesis estuviera repleta de fieles de dudosa catolicidad - y, como indica Isabella lanuzzi, la extrema patrimonialización del

toledano: BNE, Mss/ 5767: Alegato sobre estatuto de limpieza de la Sancta Iglesia de Toledo hecho por el Excmo. Señor Cardenal Silíceo, Arçobispo de Toledo, fols. $5 \mathrm{r}-88 \mathrm{v}$. 
cargo arzobispal ${ }^{22}$-la Sede Primada era lo suficientemente importante como para no permitir injerencias externas, aunque fueran las del Papado- le impulsaron a prohibir en 1551 que los jesuitas pudieran predicar y dar los sacramentos (sobre todo la eucaristía y la penitencia) en los territorios que estaban bajo su control. ${ }^{23}$ Las diversas reuniones que mantuvieron con él figuras tan importantes de la Orden como el mismo Francisco de Borja, Francisco Villanueva o Miguel de Torres no tuvieron ningún efecto, puesto que el arzobispo siempre imponía como condición para retirar su veto la imposición de un estatuto de limpieza en la Compañía. Y todo, a pesar de que los jesuitas lo intentaron por todos los medios posibles, incluso mostrando los privilegios que el Papado les había concedido en el momento de su fundación, un detalle que, según cuentan las fuentes consultadas, encendió aún más al arzobispo y le mantuvo en su agria posición durante los últimos años de su vida. ${ }^{24}$ Por tanto, el tema solamente pudo seguir adelante tras el deceso del arzobispo en 1557, abriéndose las puertas de par en par a los mílites ignacianos.

Se reactivaron las fundaciones de la Compañía en los territorios del arzobispado toledano, donde, como ya hemos ya comentado, habían llegado a Toledo y habían iniciado los contactos en Ocaña, si bien estas dos fundaciones se vieron interrumpidas durante el gobierno diocesano de Silíceo. Estos municipios se unieron a los contactos que durante los años anteriores se habían producido en lugares como Plasencia, Murcia y Cuenca, donde ya habían llegado los jesuitas y habían fundado colegio (Plasencia) o estaban en pleno proceso de negociación (Cuenca y Murcia). Todos estos territorios se encontraban por entonces en la provincia jesuítica de Castilla, desgajada de la general española en 1554 junto con la andaluza y la aragonesa. ${ }^{25}$ Después de este intermedio, volvemos al esquema basado en que la expansión jesuítica se produjo a través de los núcleos de Alcalá y Toledo. Desde la ciudad complutense se produjo la difusión jesuita en su entorno geográfico (Navalcarnero) y, fundamentalmente hacia el levante de la provincia, el obispado de Cuenca, en el que se produjeron varias fundaciones que tuvieron

22 lanuzzi, I. 2000. "Mentalidad inquisitorial y jesuitas: el enfrentamiento entre el cardenal Silíceo y la Compañía de Jesús", Cuadernos de Historia Moderna, 24: 176.

${ }^{23}$ Rodríguez Gutiérrez de Ceballos, A. 1967: 257; Pizarro Llorente, H. 2004. Un gran patrón en la corte de Felipe II. Don Gaspar de Quiroga: 63 Madrid; Polanco, J. A. de. 1894-1898. Vita Ignatii Loiolae et rerum Societatis Jesu: II, 334 Madrid.

24 "Carta de Jerónimo Nadal a Ignacio de Loyola, de Valladolid a 15 de marzo de 1554", en MNadal: I, 233-234; "Carta de Miguel de Torres a Jerónimo Nadal, de Córdoba a 16 de mayo de 1554", en MNadal: III, 832-834; Alcázar, B. de. 1710: I, 188-199; Polanco, J. A. de. 1894-1898: II, 106, 326, 338, 341, 637-643 y IV, 462, 476-477; Monumenta ignatiana: IV, 63-66, 71-73, 80-82 y 263-264.

${ }^{25}$ MNadal: I, 541-671; MNadal: II, 85, 90; MNadal: IV, 19. 
una estrecha relación con el colegio alcalaíno, algunas incluso promovidas por el doctor Vergara. Las casas jesuitas de Cuenca y Jesús del Monte tuvieron un origen similar puesto que ambas comenzaron siendo residencias de verano para los religiosos del colegio de Alcalá de Henares.

\section{Mapa 4. El influjo provincial del colegio jesuítico de Alcalá}

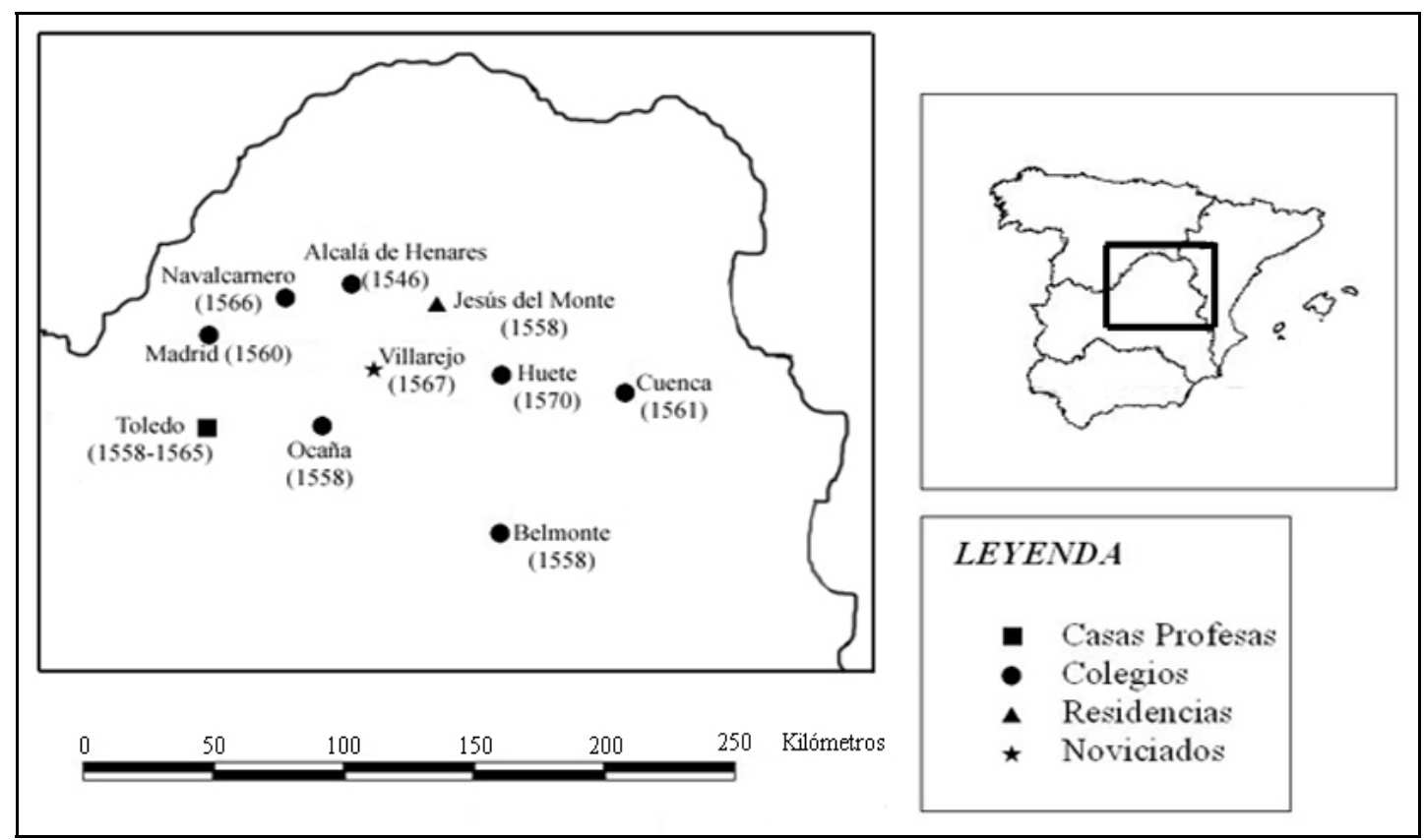

Cuenca. Por consejo y recomendación de Vergara, los jesuitas de la ciudad universitaria marchaban a Cuenca "para pasar lo recio del verano". ${ }^{26}$ Sin embargo, no fueron alojados en una casa suya, sino que intervendría ante el canónigo Pedro del Pozo, con el que Vergara estaría en contacto, que les acogió en sus casas y pretendió fundar un colegio de la Compañía en la localidad. ${ }^{27}$ Tras su muerte, tomó el relevo con la fundación el también canónigo Pedro Marquina, que tuvo a bien dotar allí unos estudios de gramática con una renta anual de 500 ducados ${ }^{28}$ Como se puede observar en la correspondencia, las negociaciones con ambos canónigos fueron muy

${ }^{26}$ ARSI, Hispania-94: Ribadeneyra, P. de. 1611. Historia de la Compañía de Jesús de las Provincias de España y parte de las del Piru y Nueva España y Philippinas, fol. $41 \mathrm{v}^{\circ}$.

27 Ibidem, fol. 41vº; B Alcázar, B. de. 1710: I, 227; Polanco, J. A. de. 18941898: IV, 424-428.

28 "Carta de Francisco de Borja a Ignacio de Loyola de Medina del Campo a 31 de julio de 1553", en MBorgia: III, 147-148; "Carta de Francisco de Borja al padre Diego Laínez, de Simancas a 7 de mayo de 1559”, en MBorgia: III, 486-487. 
duras, puesto que el primero incluso llegó a renunciar a dotar el colegio ${ }^{29}$ y con el segundo se extendieron durante varios años, por estar los jesuitas en desacuerdo con alguno de los puntos que quería imponer el canónigo Marquina. La desavenencia solía venir por las intenciones del benefactor de que la fundación fuera sólo vitalicia, con lo que no se aseguraba que los beneficiarios testamentarios continuaran con la dotación del colegio. Finalmente, en el año 1561 consiguieron que las negociaciones llegasen a buen puerto, aceptando momentáneamente esa condición, pero concediéndose "por vía de privilegio en lo que es fuera de lo común de nuestro Instituto" para evitar que fuera tomado como ejemplo en otros municipios. ${ }^{30}$ De este modo, con los 500 ducados de renta se establecieron estudios básicos de gramática y escuelas de primeras letras y doctrina para los niños del lugar, que serían impartidos por tres de los quince religiosos que residían allí (el número se vio reducido desde la cifra inicial de cuarenta). Además, en el acuerdo se establecieron los correspondientes sufragios por el fundador, tal y como aparecía dispuesto en las Constituciones jesuitas; y otra disposición por la que si la Compañía no comenzaba las aulas en el plazo de un año, las casas que ocupara el colegio pasarían a dominio de la ciudad para que sirvieran de hospital. No queda muy claro quien propuso este último punto, si la Compañía o el benefactor, puesto que ambos tendrían argumentos para ello: al igual que ocurrió en otros casos, el canónigo Marquina podría usarla para intentar que los jesuitas no se demorasen en la erección del colegio ni desviasen el uso de la dotación hacia otros fines; por otra parte, la Compañía lo utilizaría como excusa para cerrar el colegio en cualquier momento, puesto que durante la negociación y en los años siguientes se quejaron en más de una ocasión de que la dotación no era suficiente para lo que el canónigo pretendía. ${ }^{31}$ Cualquiera de las dos posibilidades es factible, pero los continuos problemas económicos que arrastró el colegio y las palabras de Jerónimo Nadal impulsan a pensar más en la segunda:

29 "Carta de Francisco de Borja al padre Diego Laínez, de Valladolid a 2 de agosto de 1559 y de Medina del Campo a 15 de agosto de 1559", en MBorgia: III, 539-540.

30 "Carta de Laínez a Nadal, de Roma a 27 de mayo de 1561", en MNadal: I, 468-469; "Carta de Borja a Pedro Marquina de febrero de 1561", en MBorgia: III, 657-658.

31 "Carta de Nadal a Diego Laínez, de Cuenca a 12 de febrero de 1561", en MNadal: I, 381-384; "Carta de Nadal a Diego Laínez, de Toledo a 3 de marzo de 1561", en MNadal: I, 395-397; Ribadeneyra, P. de. 1594. Vida del P. M. Diego Laynez: 67 en Madrid, por Pedro Madrigal; "Carta de Francisco de Borja al padre Cristóbal Rodrigo, de Roma a 18 de abril de 1562", en MBorgia: III, 683; "Carta de P. Martínez a Laínez, de Cuenca a 29 de abril de 1561", en MNadal: I, 801; "Carta de Nadal de Cuenca a principios del mes de diciembre de 1561", en MNadal: I, 569573; "Carta de Juan Bravo a Borja de Alcalá a 16 de febrero de 1571", en MBorgia: V, 563. 
"porque no da suficiente renta el señor Marquina, según el modo de fundar semejantes colegios de la Compañía, no se obliga la Compañía a sí misma a hacer aquellos ejercicios perpetuamente, sino en tanto que quisiera ella o tuviera esperanza de aumentar la renta". ${ }^{32}$

En todo caso, Cuenca era un obispado muy extenso, con unos partidos y municipios muy amplios: baste recordar San Clemente, Requena, Jorquera, Moya, Huete...

Jesús del Monte. La siguiente fundación promovida desde Alcalá fue la residencia de Jesús del Monte, que, a diferencia del caso anterior, mantuvo esta categoría dentro de la estructura jesuita. ${ }^{33}$ Según indica Pedro de Ribadeneyra, el 22 de junio de 1558 se firmó la escritura por la que el arzobispado toledano vendía a los jesuitas por 40.000 maravedíes la ermita y los bienes anexos que habían sido propiedad de una comunidad benedictina, pero que se encontraban abandonados desde el siglo $\mathrm{XV}{ }^{34}$ Además, el colegio alcalaíno se comprometió a gastar allí 600 ducados para la reparación de la ermita y la construcción de una casa que pudiera albergar, según Alcázar, hasta 70 jesuitas. ${ }^{35}$ A finales de junio llegaron los primeros jesuitas, dirigidos por Manuel López, rector del colegio de Alcalá.

Navalcarnero. La última de las fundaciones de este período que tuvieron una relación estrecha con el colegio complutense fue el centro de Navalcarnero, cuya posición dentro de la provincia osciló entre el status inicial de colegio y el de casa de probación (noviciado) desde 1575 . $^{36} \mathrm{Al}$ contrario que en los casos anteriores, lo que une esta fundación con Alcalá no es que el benefactor estuviera relacionado de alguna manera con el colegio de esa localidad. La conexión entre los centros jesuitas de Alcalá y Navalcarnero

32 "Memorial sobre la fundación del colegio de Cuenca de Nadal, febreromarzo de 1561", en MNadal: IV, 735-737.

33 Sobre las residencias jesuíticas y toda la problemática que encerraron, remitimos a lo dicho en: Martín López, D. 2011. "La provincia jesuítica de Toledo en tiempos de Francisco de Borja (1551-1572)", en E. García Hernán y M. P. Ryan (eds.), Francisco de Borja y su tiempo (1510-1572). Política, religión y cultura en la Edad Moderna: 481-522 Valencia-Roma. Sobre el caso concreto de Jesús del Monte, véase: ARSI, Toletana-44, exp. 69: Pro y contra de la Residencia de Jesús del Monte, redactado por el P. Manuel, Toledo, 30 de mayo de 1575.

34 ARSI, Hispania-94: Ribadeneyra, P. de. 1611: fol. 63v'; Alcázar, B. de. 1710: I, 278.

${ }^{35}$ Alcázar, B. de. 1710: I, 355.

${ }^{36}$ ARSI, Hispania-94: Ribadeneyra, P. de. 1611: fol. 87ro; Astrain, A. 19021925: II, 241. 
procede de los problemas que tuvo la Compañía con Juan Bautista de Madrid y la concesión de bulas papales para que éste pudiera destinar algunas rentas de su curato para la fundación. Tras la negativa del papa Pío IV en 1564, su sucesor, Pío $\mathrm{V}$, dio los permisos oportunos para que dicha dotación se realizase a partir de 1566, ${ }^{37}$ momento a partir del cual comenzaron a llegar los jesuitas $y$, con ellos, los problemas económicos para el colegio de Navalcarnero por el pago de las bulas pontificias. Según se extrae de la correspondencia mantenida entre la provincia y Roma, Juan Bautista de Madrid se negó a pagar los 1.200 ducados correspondientes a la consecución de dichas bulas, indicando que ese gasto no estaba incluido en su dotación y que la Compañía de Jesús debía hacerse cargo de ese pago. Éste se realizó en torno al 29 de mayo de 1565, antes de que el primer jesuita pisara el colegio navalcarnerense, cuando el padre Polanco notificó que la deuda con la Santa Sede había sido sufragada por el colegio de Alcalá, ${ }^{38}$ un detalle que nos muestra que las provincias no eran un mero conglomerado de colegios, sino la suma de todos ellos, y que para entender la historia de uno, hay que conocer la historia del resto y las relaciones que se establecieron entre ellos. A partir de entonces, el colegio de Navalcarnero buscó la forma de solventar la deuda que tenía con sus hermanos de religión de Alcalá. Como se extrae de la correspondencia, los jesuitas de Navalcarnero tuvieron que vender algunas de sus posesiones para afrontar el pago, tal y como se extrae, por ejemplo, de una carta de Francisco de Borja de 1570, en la que se anuncia que el colegio sevillano compraba los 515.000 maravedíes de censo que el colegio de Navalcarnero tenía en Utrera. ${ }^{39}$ La deuda se terminó de saldar en 1572.

Belmonte, Villarejo y Huete. Las otras fundaciones que se produjeron en estos años en el obispado conquense no tuvieron tanta relación con el colegio alcalaíno como las que hemos hecho mención, aunque no por eso no debemos referirnos a ellas, ya que, siguiendo con lo dicho unas líneas más arriba, la evolución de cada uno de estos colegios estuvo ligada a la del resto. Como se puede observar en la documentación económica que guardan los depósitos del Archivum Romanum Societatis lesu, a partir de la década de 1570 estos centros jesuitas se unieron en varias ocasiones para oponerse a los intentos del obispo de Cuenca para que, contra lo dispuesto en los privilegios pontificios que tenían los jesuitas, pagasen el diezmo como el resto

37 Astrain, A. 1902-1925: II, 241; ARSI, Hispania-94: Ribadeneyra, P. de. 1611: fol. 87r ${ }^{\circ}$; Alcázar, B. de. 1710: II, 120.

38 "Carta de Juan Alfonso de Polanco al padre Saavedra de Roma a 29 de mayo de 1565", en MBorgia: VII, 315-316.

39 "Carta de Francisco de Borja al padre Juan de Cañas, de Roma a 4 de septiembre de 1570", en MBorgia: V, 489. 
de órdenes religiosas. ${ }^{40}$ Por otra parte, la llegada de jesuitas a estas localidades se debió en buena parte a que anteriormente se habían establecido en el entorno. Por ejemplo, en el caso de Villarejo llegaron entre finales de la década de 1550 y principios de la de 1560, cuando la semilla jesuita ya se había plantado desde hacía unos años en las poblaciones de Alcalá, Ocaña y Jesús del Monte, localizadas a escasas jornadas de allí. La de Huete responde a una explicación similar, puesto que era un lugar de paso entre Alcalá y Cuenca. Sin embargo, la fundación de Belmonte resulta ciertamente diferente, puesto que, como se puede observar en el mapa de fundaciones de la provincia, es un municipio aislado del resto y que, además, fue uno de los primeros lugares de la zona en los que la Compañía se puso de acuerdo con un benefactor para la fundación de un colegio. Además, este caso tuvo la especificidad de que al poco tiempo de comenzar las clases, su población estudiantil creció tanto que tuvieron que fundarse casas de convictores y porcionistas para alojar a los estudiantes que llegaban de otros municipios y que no habían ingresado en la Compañía. ${ }^{41}$ Según se puede observar por la correspondencia de los padres Borja y Nadal, comisarios de la provincia en estos años, los alumnos externos fueron todo un problema para los jesuitas belmonteños, fundamentalmente por dos cuestiones relacionadas con la financiación de estas casas: por una parte, los convictores debían limosnear para poder pagar el alquiler del alojamiento a los jesuitas, ${ }^{42}$ con lo que suponemos que su sostenimiento pesaría más a los religiosos que a sus inquilinos, a los que costaría bastante reunir la cantidad acordada; por otra parte, aunque relacionado con esto, la gente entendía que estos convictores eran jesuitas porque pedían limosna para pagar la casa de los religiosos, con el consiguiente daño que sus malos comportamientos conllevaban por la correlación que se podía establecer entre jesuitas y actos tan poco decorosos. Luchar contra este tipo de opiniones y actuaciones fue algo primordial en las primeras décadas de existencia de la Orden, en las que se dieron a conocer en la sociedad, especialmente en el área rural, donde era más difícil que llegaran noticias de ese tipo. La solución al respecto fue reducir o eliminar los lazos existentes entre los convictores y los jesuitas más allá del mundo educativo y "que se entienda que de ellos no viene utilidad ninguna al

${ }^{40}$ ARSI, FG/1371, busta 4, exp. 11; ARSI, FG/1445, exps. 3, 17, 40-45; ARSI, FG/1652, exps. 8-10.

41 "Carta de Jerónimo Nadal al padre Sebastián Romeo, de Alcalá a 23 de febrero de 1562", en MNadal: I, 646; MNadal: II, 87; "Carta de Pedro Sevillano a Francisco de Borja, de Belmonte a 8 de abril de 1565", MBorgia: VII, 304.

42 "Carta de Juan Alfonso de Polanco al padre Gonzalo González, provincial de Toledo, de Roma a 10 de julio de 1566", en MBorgia: VII, 589-590; "Carta de Francisco de Borja al padre Pedro Sevillano, de Roma a 20 de diciembre de 1566", en MBorgia: VII, 765; "Carta de Pedro de Ribadeneyra a Everardo Mercuriano, de Jesús del Monte a 7 de octubre de 1577", en MRibadeneyra: I, 785. 
colegio". ${ }^{43}$ La donación de doña Francisca Ponce de León en 1582 solventaría el problema económico provocado por dichas casas.

A continuación, pasamos del área oriental de la provincia de influencia alcalaína, a la zona sur, de influjo toledano. En los años siguientes a que los jesuitas se asentaron en la Sede Primada y se consolidaron con el establecimiento allí de la Casa Profesa de la Provincia, desde Toledo se iniciaron diferentes campañas misionales hacia el Sur y el Este, concretamente hacia los Montes de Toledo y La Mancha. A pesar de que los trabajos de evangelización en estas zonas se desarrollaron en los siguientes generalatos y que no hubo fundaciones allí hasta principios del siglo XVII, haremos una breve mención a las misiones interiores que tuvieron lugar en esos ámbitos.

Montes de Toledo. En el mapa 3 pudimos observar que las fundaciones que tuvieron lugar o se iniciaron en tiempos de Diego Laínez se concentraron en la zona norte de la provincia, dejando un llamativo vacío en la franja meridional de la misma, en el obispado de Badajoz y la amplísima zona sur del arzobispado de Toledo, esto es, el Campo de Almagro-Calatrava, Ciudad Real, Infantes, incluso Alcaraz (sin olvidar la zona santiaguista de Ocaña a Uclés). Este detalle lleva a pensar en un primer momento que los jesuitas se asentaron en las zonas más urbanizadas o con mayor cantidad de población y soslayaron los ámbitos más dispersos y rurales, en los que les sería más complicado conseguir apoyos para asentarse en ese entorno. Sin embargo, la documentación y la evolución de la provincia nos muestran que esto no fue exactamente así. Es innegable que los primeros lugares en los que los jesuitas se dieron a conocer y consiguieron dotaciones eran núcleos de población urbana de cierta consideración, como la ciudad universitaria de Alcalá de Henares, Toledo y las ciudades cabeza —o cercanas a ella- de algún obispado, como los casos de Plasencia, Murcia y Cuenca. También hay que tener en cuenta la situación de la villa de Madrid y la Corte de Felipe II en la provincia, puesto que, aunque los centros jesuitas que había allí tardasen en desarrollarse y adquirir importancia, es un aspecto que no hay que dejar de lado por la gran cantidad de oportunidades que fundamentalmente la Corte ponía a disposición de los jesuitas. ${ }^{44}$ Pues bien, los mílites jesuitas no se

43 "Carta de Juan Alfonso de Polanco al padre Gonzalo González, de Roma a 25 de abril de 1566", en MBorgia: VII, 493; "Carta de Pedro de Ribadeneyra a Everardo Mercuriano, de Jesús del Monte a 7 de octubre de 1577", en MRibadeneyra: I, 786.

${ }^{44}$ Para más información sobre las relaciones que mantuvieron los jesuitas con el entorno cortesano madrileño, así como los contactos que hubo desde allí con la Corte pontificia, puede consultarse la obra de José Martínez Millán y la tesis doctoral 
circunscribieron a esas localizaciones urbanas, que utilizaron como enclaves desde los que poder lanzar avanzadillas hacia aquellos territorios en los que una orden tan joven y desconocida como la Sociedad de Jesús podría encontrarse con dificultades para lograr asiento. De este modo, y como nos muestra la documentación que puede consultarse en el Borgo romano, ${ }^{45}$ a mediados de la década de 1560 se produjeron los primeros movimientos misionales desde Toledo hacia el Sur, concretamente hacia la zona de los Montes de Toledo. ${ }^{46}$

de Esther Jiménez Pablo, investigadores del Instituto Universitario "La Corte en Europa" (IULCE) y de J. J. Lozano Navarro, de la Universidad de Granada: Martínez Millán, J. 1998. "Transformación y crisis de la Compañía de Jesús (1578-1594)" en F. Rurale (a cura di): I Religiosi a Corte. Teologia, Politica e Diplomazia in Antico Regime: 101-129. Roma, Bulzoni editore; Martínez Millán, J. 2003. "La crisis del "partido castellano» y la transformación de la Monarquía Hispana en el cambio de reinado de Felipe II a Felipe III", Cuadernos de Historia Moderna Anejo II: 11-38; Jiménez Pablo, E. 2011. La lucha por la identidad en la Compañía de Jesús: entre el servicio a Roma y el influjo de la monarquía hispana (1573-1643) tesis doctoral inédita leída en la Universidad Autónoma de Madrid, Facultad de Filosofía y Letras, Departamento de Historia Moderna, el 29 de septiembre de 2011 (http://hdl.handle.net/10486/7772); Lozano Navarro, J. J. 2005. La Compañía de Jesús y el Poder en la España de los Austrias Madrid.

${ }^{45}$ ARSI, Hispania-103, fols 380r-381v: Estos son los dieciocho lugares de los Montes de Toledo donde se ha de fundar y aunque van veinte y siete, son los demás circunvecinos. El documento está fechado en el año 1566. El esquema 5 está sacado de aquí. Las cifras que aparecen hacen referencia a la distancia en leguas que existía entre las diferentes localidades.

${ }^{46}$ Sobre la importancia y significado de las misiones jesuitas ver, los trabajos del profesor Federico Palomo: Palomo, F. 2004. "De algunas cosas que sucedieron estando en misión: espiritualidad y escritura misionera en la Península lbérica (siglos XVI y XVII)", en A Companhia de Jesus da Península Ibérica nos séculos XVI a XVIII: espiritualidade e cultura: I, 119-150. Oporto; Palomo, F. 2007. "Limosnas impresas. Escritos e imágenes en las prácticas misioneras de interior en la Península Ibérica (siglos XVI-XVIII)", Manuscrits. Revista d'Història Moderna 25: 239-265; por supuesto Palomo, F. 2003. Fazer dos campos escolas excelentes: os Jesuítas de Évora e as missôes do interior em Portugal (1551-1630) Lisboa. 
Mapa 5. Esquema de las misiones jesuíticas efectuadas por los Montes de Toledo, c. 1566.

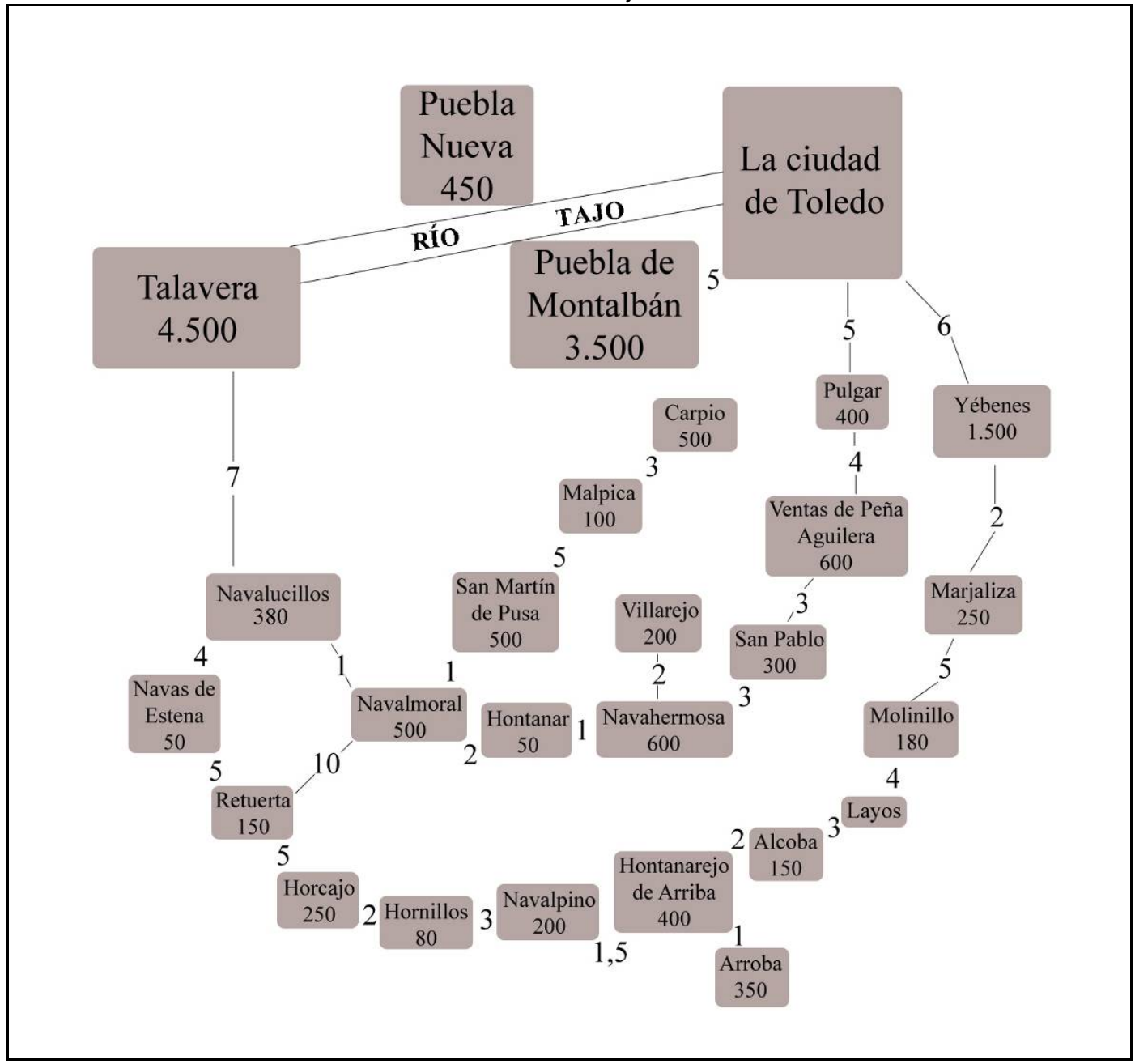

Se describe aquí con detalle cuáles eran las poblaciones a las que se tenía intención de acudir, el número de vecinos (familias) que las habitaban y las distancias que las dividían en leguas; incluso se sugería que de los 27 municipios que aparecen en el documento, podía aspirarse a realizar 18 fundaciones. Desconocemos cuáles serían finalmente las localidades elegidas, aunque si limitamos nuestra búsqueda a la comarca natural montañosa — de este modo obviamos los núcleos de Toledo, Talavera, Puebla Nueva y La Puebla de Montalbán- y a las poblaciones con mayor número de habitantes, los 18 lugares a los que se hace referencia en el título del documento serían, por orden demográfico: Yébenes, Ventas de [con] Peña Aguilera, Navahermosa, San Martín de Pusa, Navalmoral, Carpio, Pulgar, Hontanarejo de Arriba, Navalucillos, Arroba, San Pablo, Marjaliza, Horcajo, Navalpino, Villarejo, Molinillo, Retuerta y Alcoba. En estos momentos desconocemos cuál fue el grado de éxito que tuvieron en estas misiones, aunque no descartamos que tuviera cierta consideración, puesto que unos 
años después de que se creara la Casa Profesa en Toledo, aparecen vinculadas a ella, como residencia, unas casas en el lugar de Casasbuenas, que se encuentra a pocos kilómetros de Layos, y en las Cartas Anuales de finales del siglo XVI se hace referencia a algunos trabajos en los Montes de Toledo. ${ }^{47}$ Hasta aquí tratamos las misiones interiores de los jesuitas toledanos a lo largo de los Montes de Toledo, que volverán a ser objeto de un estudio más amplio en futuras investigaciones.

La Mancha. Por otra parte, desde Toledo también se dirigieron otras campañas hacia los territorios meridionales de la provincia, a diversas poblaciones de la comarca de La Mancha. Es posible que también se enviara alguna desde Ocaña y, en menor medida, desde Belmonte por la proximidad geográfica, pero lo más seguro es que el centro toledano, con su categoría de Casa Profesa, fuera el encargado de llevar el peso de la evangelización en esta zona, también fundamentalmente rústica. Además, el aumento del favor arzobispal que fueron consiguiendo con el paso de los años también influiría en ello, pudiéndose afirmar que algunas de las misiones manchegas fueron impulsadas por el cabildo catedralicio, que se aprovecharía de los trabajos jesuitas para mantener la ortodoxia en su diócesis en un contexto de ejemplarizante aplicación de Trento. ${ }^{48}$ Poseemos algunas noticias acerca de los trabajos pastorales en La Mancha, aunque son un tanto fragmentarias. Hay constancia de que la Compañía de Jesús pasó por esta comarca en la década de 1550 , concretamente en Daimiel, ${ }^{49}$ y que las misiones en la zona se intensificaron a partir de la década de 1580, como se desprende de la lectura de las Cartas Anuales. ${ }^{50}$ Estas noticias hacen más difícil entender qué

47 En la de 1599: "Eum tractum (quos montes Toletanos appelant) duo e Nostris pedites, rogataque stipe viuentes, multa ruditate, et ignorantia liberantur, et audiendis confessionibus plurimum adiuverunt" (Recorren a pie este territorio al que llaman Montes de Toledo dos sacerdotes, viviendo de limosnas, y allí son liberados los que viven en condiciones durísimas y en la ignorancia. $\mathrm{Y}$ han ayudado muchísimo a los de allí con las confesiones), p. 497.

${ }^{48}$ Fernández Collado, A. 1996. Concilios toledanos postridentinos. Estudio y edición Toledo.

${ }^{49}$ MNadal: III. 832-834.

50 En la de 1589: "Ex hac Domo, quod factum est quinque annis continuis, itum Quadragesima ad Pontem Archiepiscopi (oppidum est huius dioeceseos) omnesque ad caelestem mensam rite praeparati, et ad mutuam concordiam multi adducti" (De esta casa, lo que se ha hecho durante cinco años consecutivos, se ha ido en misión en Cuaresma a Puente del Arzobispo (ciudad de esta diócesis) y todos [sus habitantes] se prepararon para el banquete celestial según el rito y muchos guiados a una mutua concordia), p. 343. En la de 1590: "Igitur ex Optensi Moratam (nomen oppidi est non ignobilis ad ripam Tagi) extortus oppidanorum precibus iuit sacerdos cum socio, et honorifice exceptus. Gratissimum visum munus instituendae pueritiae ad Christianam doctrinam. Vel ex quattuor concionibus tantus fructus, ut qui semel anno communicarent, reiicerentque confessionem in extremam 
es lo que pudo ocurrir en aquellos territorios para que, habiéndose dado a conocer en fechas tan tempranas, tengamos que esperar a principios del siglo XVII para que se produjera la primera fundación manchega en Almagro. Las hipótesis que pueden manejarse para explicar este fenómeno son diversas. En primer lugar, hay que atender a la ya mencionada prioridad urbana que tuvieron los jesuitas y que, en caso de que se produjera en el ámbito rural, ésta debía realizarse con una dotación suficiente, puesto que allí las posibilidades de recaudación de limosnas y de obtención de ayudas eran inferiores a las existentes en la ciudad. Desde luego que esta realidad no era privativa de los jesuitas sino que formó parte del modus operandi de casi todas las órdenes religiosas mendicantes o de recolección que se abrieron paso desde la plena Edad media.

Quadragesiman, fere omnes utrumque praestiterint ieiunio ineunte. Daimelium oppidum est in Oretanis, ita plenum litigiorum ac simultatum, ut nemo fere sit, quem ea pestis non attingat." (Así pues, un sacerdote, obligado por la solicitud de los ciudadanos y elegido por sus méritos, emprendió el camino del Optense a Morata (nombre de ciudad no desconocida junto a la orilla del Tajo) con un compañero. Pareció(le) gratísima la tarea de formar a niños para la doctrina cristiana. Tanto fue el fruto de cuatro reuniones, que quienes comulgaban una sola vez al año y dejaban la confesión para el final de la Cuaresma, casi todos ejercieron lo uno y lo otro al empezar el ayuno. La ciudad de Daimiel está en la Oretania, tan llena de litigios y enemistades que no hay casi nadie a quien no ataña algo de esa calamidad...), pp. 633-654. En la de 1600: "Sex aut octo missi sunt ad opida ciuibus sopiosa; ad quorum aliqua nec nomen nostrae Societatis peuenerat, unde et nostros fugiebant, quasi nihil aliud quam sua ipsi quaererent, et largas eleëmosynas aucuparentur..." (Seis $u$ ocho han sido enviados a poblaciones abundantes en vecinos, a algunas a las que ni siquiera había llegado el nombre de nuestra Compañía, a consecuencia de lo que incluso rehuían a los nuestros como si no buscaran éstos otra cosa que su propio provecho y anduvieran en busca de copiosas limosnas), p. 146. En la de 1601: "Septem e nostris in diuersa loca, quae maxime illorum opera indigebant, digressi: ubi Societatis ministeria fructuose posita..." (Siete de los nuestros marcharon a diversos lugares que estaban necesitados de abundante ayuda, donde se han ofrecido fructíferamente los oficios de la Compañía), pp. 184-188. En la de 1604 se dice que predicaron en Membrilla, localidad situada a pocas jornadas de Daimiel y de Almagro: "Itaque nostrorum suasu lites et odia deposita, quin etiam se mutuo amplexi et osculati sunt, gratia reconciliata, et familiaritas, tanta cum populi admiratione, ut passim dictitarent, nihil iam esse daemoni negotii Membrille, id nomen est loci, nisi nouam de integro telam ordinatur." (Se depusieron peleas y odios por intercesión de los nuestros, de modo que incluso se besaron y abrazaron, y así se recuperó su amistad y familiaridad, con tal admiración del pueblo que a cada paso dijeran que ya nada tenía que hacer el diablo en Membrilla - ese era el nombre del lugar-a no ser que se recompusiera de nuevo la trama por entero), $p$. 113. En la de 1610: "Tertia denique expeditio suscepta ad Daymielem oppidum celebre a Calendis Februariis ad affectum usque lunium". (La tercera expedición, a la célebre ciudad de Daimiel, fue desde el primero de febrero hasta junio), p. 120. 
Al margen de esta cuestión estratégica, otra peculiaridad que debemos tener en cuenta es la especial distribución geo-político-institucional de la zona novocastellana, del antiguo Reino de Toledo, con fragmentos de la Extremadura leonesa y el Reino de Murcia. Si hay algo que decir, por obvio, es que allí asistimos al predominio del señorío de algunos obispados (entre ellos el poderosísimo toledano), de algunas ciudades importantes (con categoría de tales y con voto en Cortes), y sobre todo de las órdenes militares, no sólo las genuínamente castellanas (Calatrava, Santiago, Alcántara) ${ }^{51}$ sino también la internacional de San Juan de Malta. ${ }^{52}$ Como vemos, el realengo era muy limitado (pocas ciudades, incluyendo Ciudad Real pero casi excluyendo Guadalajara), y así casi todo pasaba por la jurisdicción eclesiástica, vía episcopal, vía en la mixtura del Real Consejo de Órdenes (Militares). En efecto, conocemos la intervención de dicho consejo en los casos de Ocaña, Segura de la Sierra y Daimiel, en donde actuó por la petición de un tercero y no motu proprio ${ }^{53}$ esto es, que no se encontraron razones para cancelar el proceso fundacional, lo cual nos hace dudar de la existencia de una relación causa-efecto entre la resistencia u oposición de las Órdenes Militares y la falta y retraso de fundaciones jesuitas en La Mancha. En todo caso, conocemos que precisamente en los mismos años en que se está constituyendo la provincia toledana, y durante todo el siglo XVI (y aún después) el tráfico de ventas de encomiendas y señoríos militares fue muy intenso (bajo la ambición tanto de los grandes aristócratas como de miembros de la familia real), y ello supuso una inseguridad o inestabilidad en esta amplia como aparentemente vacua zona central.

51 Véase para un panorama general y para esta zona en particular las ponencias del libro López-Salazar Pérez, J. (coord.) 2000. Las Órdenes Militares en la Península Ibérica, vol. II: Edad Moderna, Cuenca, especialmente págs. 1.5851.720 y $1.827-1.923$.

52 Se trata del compacto Gran Priorato de Castilla, una gran lengua de tierra que abarca desde Lillo-Manzaneque-Tembleque, pasando por Guadalerzas-Urda, llegando hasta Argamasilla de Alba y volviendo por Alcázar de San Juan-Quero, el estado señorial-militar más grande de toda la zona; y más hermético. Véase LópezSalazar Pérez, J. 2009. "El Gran Priorato de San Juan: señorío y conflictividad en la Edad Moderna”, en F. Ruiz Gómez y J. M. Molero García (eds.), La Orden de San Juan, entre el Mediterráneo y la Mancha: 219-324. Cuenca; Aranda Pérez, F.J. y Morales Sánchez-Tembleque, M. 2010. "El régimen señorial de los Prioratos de San Juan en la Mancha en el primer tercio del siglo XVII", en F. Ruiz Gómez y J. M. Molero García (eds.), La Orden de San Juan en tiempos del Quijote: 207-233. Cuenca.

${ }^{53}$ En el caso de Daimiel, la intervención del Consejo de Órdenes se debió a los problemas que tuvieron con el párroco de Santa María y está fechada en 30 de julio de 1610. Puede ser consultada en $\mathrm{A}$ (rchivo) $\mathrm{H}$ (istórico) $\mathrm{N}$ (acional), OOMM, Consejo, leg. 3134. 
Relacionado también con este factor se encuentra la atribución del carácter converso que rodeó a la Compañía de Jesús en sus primeras décadas de existencia y su negativa a implantar un estatuto de limpieza de sangre, a lo que antes hemos hecho mención. A pesar de las dudas mostradas unas líneas más arriba, traemos este detalle a colación porque, como se puede observar en la cita referida a las Cartas Anuales, a partir de finales del siglo XVI se produjo un aumento de las misiones a esta zona, coincidiendo con la Congregación General de los años 1592-1593 y el establecimiento en ella de un estatuto de limpieza de sangre. Sea como sea, lo único que parece cierto es que los jesuitas tardaron en ganarse el favor de los manchegos, aunque desconozcamos el porqué exacto. Solamente un estudio minucioso de la intervención de los "hermanos de San Ignacio" en esta zona, atendiendo a los distintos casos y a las diversas variables que pudieron actuar (relación con la sociedad, religiosos, Consejo de Órdenes...), aportará algo de luz a las dudas existentes en la actualidad.

Fundaciones desarrolladas durante el generalato de Laínez ${ }^{54}$

\begin{tabular}{|c|c|c|}
\hline Lugar & Fecha & Benefactor \\
\hline Plasencia & 1554 & $\begin{array}{c}\text { Obispo Gutierre de Vargas y } \\
\text { Carvajal }\end{array}$ \\
\hline Murcia & 1554-1557 & Obispo Esteban de Almeyda \\
\hline Belmonte & $1554-1558$ & $\begin{array}{l}\text { Diego López Pacheco, Marqués de } \\
\text { Villena y Duque de Escalona }\end{array}$ \\
\hline Cuenca & 1554-1561 & Pedro del Pozo/Pedro Marquina \\
\hline Jesús del Monte & 1558 & Alonso Ramírez de Vergara \\
\hline Toledo & $1558-1562$ & Sin fundador por ser Casa Profesa \\
\hline Ocaña & $1555-1558$ & Luis de Calatayud \\
\hline Madrid & $1556-1560$ & $\begin{array}{c}\text { Leonor de Mascareñas/línigo } \\
\text { Fernández de Velasco, Condestable } \\
\text { de Castilla }\end{array}$ \\
\hline Villarejo de & $1561-1567$ & Juan Pacheco de Silva y Jerónima \\
\hline
\end{tabular}

54 Incluimos en este cuadro aquellas fundaciones que tuvieron sus inicios durante los años en los que Diego Laínez fue prepósito general, tanto las que se materializaron en ese generalato como las que no lo hicieron hasta un poco más tarde, aunque los primeros contactos se produjeran en estos años, como es el caso de Oropesa. 
TORNO AL GENERALATO DE DIEGO LAÍNEZ (1556-1565)

\begin{tabular}{|c|c|c|}
\hline Fuentes & & de Zúñiga y Mendoza \\
\hline Navalcarnero & $1564-1566$ & Juan Bautista de Madrid \\
\hline Oropesa & $1555-1570$ & $\begin{array}{c}\text { Fernando Álvarez de Toledo, conde } \\
\text { de Oropesa/Francisco de Toledo, } \\
\text { virrey del Perú }\end{array}$ \\
\hline
\end{tabular}

Extremadura. Respecto al vacío al que hacíamos referencia en la zona de los obispados de Coria y Badajoz (con los amplios partidos de Alcántara, Valencia de Alcántara, Badajoz, Jerez de los Caballeros, Llerena, Villanueva de la Serena, Mérida y Montánchez, Cáceres y Trujillo), podría ser explicado siguiendo lo que afirmábamos unas líneas más arriba, según lo cual los jesuitas no contemplaban como algo prioritario las fundaciones en el más precario territorio agrario. Según se puede observar en la correspondencia existente entre la Provincia y Roma a lo largo del siglo XVI, solamente permitían fundar un colegio si la dotación era de una cantidad suficiente por considerable. No obstante, al igual que hemos afirmado en relación a las misiones de los Montes de Toledo y de La Mancha, será necesaria una investigación más profunda para comprender los primeros pasos de los jesuitas en esta zona y saber porqué, a pesar de que el colegio de Plasencia se fundó en 1554 y de que hubo varias misiones en la zona ${ }^{55}$ hasta el siglo $\mathrm{XVII}$ no consiguieron consolidarse en la zona con las fundaciones de los colegios de Trujillo y Llerena.

\section{PLASENCIA Y MURCIA, INCORPORACIONES "NO-CASTELLANAS"}

Para completar el panorama provincial jesuítico-toledano, es necesario comentar dos casos peculiares y geográficamente extremos dentro de dicha provincia, a saber: los colegios de Plasencia y de Murcia. Aparte de que fueron los únicos fundados en estos años por obispos -y así siguió siendo hasta las fundaciones del cardenal Gaspar de Quiroga en la década de 1580 - ambos colegios tienen la particularidad de que en sus orígenes no pertenecieron a la provincia castellana, de cuyos territorios se desgajó fundamentalmente la circunscripción toledana, como se puede observar si comparamos los mapas provinciales que han aparecido a lo largo de estas páginas. Como veremos a continuación, los colegios placentino y murciano pertenecieron inicialmente a las demarcaciones andaluza y aragonesa, pero acabaron integrándose a partir de 1562 en la Provincia de Toledo por razones de tipo estructural y por los designios y las querencias especiales de sus fundadores.

55 En la Carta Anual de 1581 se habla de los "batuecos", "sunt in extrema Hispania Lusitanis proximi" (se encuentran en los confines de España, próximos a los lusitanos), p. 114. 
Plasencia. La primera de las dos fundaciones fue la de Plasencia, ${ }^{56}$ impulsada por el obispo don Gutierre de Vargas y Carvajal y materializada en 1554; aunque según cuentan los historiadores jesuitas, los contactos del obispo con la Compañía comenzarían durante y, sobre todo, después de las primeras sesiones del Concilio de Trento, en el año $1552 .{ }^{57}$ De este modo, en 1554 llegaban los primeros jesuitas, entre los que destacaban nada menos que Francisco Villanueva, Francisco de Borja, Dionisio Vázquez y Bartolomé de Bustamante, quien se encargó de preparar las trazas y de las obras del colegio, que se extendieron en el tiempo hasta más allá de 1562, tal y como se desprende del testimonio del visitador Nadal. ${ }^{58}$ En un principio, la fundación se circunscribía en la provincia jesuítica de Andalucía, de tal manera, que incluso Francisco de Borja proponía a Ignacio de Loyola en octubre de ese año que lo que debía situarse en Plasencia tenía que ser una "casa de aprobación para perfeccionarse los sujetos" —un noviciado, en puridad- y que perteneciese a la provincia bética. ${ }^{59}$ Sin embargo, poco después pasó a formar parte de la provincia castellana, como se observa en la carta que Francisco de Borja envía a Ignacio de Loyola el 23 de agosto de $1555 .{ }^{60}$ Desconocemos cuáles fueron las motivaciones para que en el plazo de poco menos de un año, los límites provinciales se modificasen tanto y la diócesis placentina pasara a integrarse en territorio castellano. Como ya se ha reflexionado más arriba, hay que tener en cuenta que las primeras décadas de vida de la Compañía de Jesús estuvieron rodeadas de un continuo trasiego en busca de un sistema y una estructura que se ajustaran a las pretensiones del ideal ignaciano. De este modo, sin llegar a afirmar que los jesuitas improvisaron en estos años hasta dar con la fórmula perfecta, sí queda bastante claro que la Compañía realizó diversas modificaciones en su estructura para irse adecuando a las condiciones y circunstancias a las que tuvo que hacer frente. El cambio de provincia que sufrió el colegio placentino puede ser un ejemplo de ello, como lo fue la creación y modificaciones que

${ }^{56}$ Para más información sobre el colegio jesuita de Plasencia, véase: Higuera, Jerónimo Roman de la. 1600. Historia del colegio de Plasencia de la Compañía de Jesús, manuscrito inédito del Archivo Histórico Provincial de Castilla de la Compañía de Jesús (Alcalá de Henares); Peña Gómez, Ma P. de la. 1991. "Estudio arquitectónico del colegio jesuítico de Plasencia". Norba-arte 11: 39-50; y el apartado correspondiente que se le dedica en el trabajo ya citado de David Martín López. 2011: 494-496.

57 ARSI, Hispania-94: Ribadeneyra, P. de. 1611: fol. 32v; Alcázar, B. de. 1710: I, 230; Rodríguez Gutiérrez de Ceballos, A. 1967: 79.

58 "Carta de Nadal al padre Sebastián Romeo de Alcalá a 23 de febrero de 1562", en MNadal: I, 639.

59 "Carta de Francisco de Borja a Ignacio de Loyola de Plasencia a 31 de octubre de 1554", en MBorgia: III, 178.

60 "Carta de Borja a Ignacio de Loyola, de Simancas a 23 de agosto de 1555", en MBorgia: III, 239. 
sufrieron los cargos de Provincial, Comisario y Asistente en esos mismos momentos.

Murcia. La cuestión del colegio murciano ${ }^{61}$ es diferente a la que acabamos de comentar, a pesar de que también tuviera como benefactor a un prelado de la Iglesia, el obispo de Cartagena, Esteban de Almeyda. Como veremos a continuación, la fundación y los primeros pasos del colegio murciano estuvieron siempre condicionados por la voluntad y los intereses del obispo, hasta el punto de conseguir que sus territorios obispales cambiasen de provincia de adscripción. Al mismo tiempo, este caso es una muestra más de la permisividad que practicaron los jesuitas con sus benefactores, aviniéndose a cualquier petición —-más bien, mandamiento u orden- por comprometida que fuere, con tal de conseguir una asignación suficiente para fundar un colegio. En estas situaciones, la manera de actuar era el establecimiento en las capitulaciones de una fórmula según la cual se indicaba que una determinada condición era aceptada de forma extraordinaria para evitar que se convirtiera en una práctica común en fundaciones futuras o fuera objeto de reclamación por parte de los que ya habían ayudado a erigir alguna casa. Así, el obispo Almeyda entró en contacto con la Compañía a través de su amistad con Francisco de Borja antes incluso de que éste se convirtiera en ignaciano y que con su ejemplo consiguiera muchas adhesiones para la por entonces joven orden religiosa, sobre todo por su influjo en la nobleza. Una de estas adhesiones fue la del propio obispo cartagenero, que pronto inició las negociaciones para instituir un colegio en su diócesis, aunque no en la sede episcopal sino en la próspera ciudad de Murcia, cabeza del reino homónimo. ${ }^{62}$

Los primeros jesuitas comenzaron a llegar a Murcia en 1554, con el padre Bautista de Barma a la cabeza. La buena impresión que este religioso causó en el obispo es un factor determinante para entender la reacción del obispo cuando el padre Barma murió, aunque el principal aspecto que hay que tener en cuenta es la propia personalidad del obispo, que difícilmente admitía una respuesta negativa a sus peticiones y que incluso amenazó en más de una ocasión con anular la dotación fundacional. ${ }^{63} \mathrm{~A}$ lo largo del

${ }^{61}$ Para más información sobre la Compañía de Jesús en el entorno murciano, véase: Arnaldos Pérez, M. 1973. Los jesuitas en el reino de Murcia (apuntes históricos) Madrid; Játiva Miralles, M. V. 2008. La biblioteca del colegio de San Esteban de los jesuitas de Murcia Murcia.

62 Si atendemos a la totalidad de partidos del Reino de Murcia, tengamos en cuenta que por entonces contaba con el de Murcia, propiamente dicho (que abarcaba toda la parte central del reino), pero también el de Cartagena, Lorca, Hellín y Chinchilla (del que se desgajaría después Albacete).

63 "Carta de Polanco a Borja de Roma a 9 de junio de 1560", en MBorgia: VII, 129; "Carta de Borja a Diego Laínez, de 5 de junio de 1560", en MBorgia: III, 614615. 
período de negociaciones para la dotación del colegio murciano, los jesuitas tuvieron que hacer frente a una buena cantidad de demandas que eran difícultosas de cumplir. Así, por ejemplo, en torno al año 1555 solicitó en varias ocasiones que Francisco de Borja residiera en su diócesis para poder tenerlo más cerca y disfrutar de su compañía, ${ }^{64}$ algo que resultaba en aquellos momentos harto complicado debido a la importante labor que el antiguo duque de Gandía estaba desarrollando en aquellas fechas para dar a conocer a los jesuitas en toda la Península Ibérica. Otro aspecto de arduo convencimiento para el obispo fue que no todos los religiosos que viviesen en el colegio tuvieran que dedicarse a lo pastoral, lo cual iba en contra del Instituto jesuita, que ordenaba que en cada casa existieran una serie de jesuitas dedicados a labores auxiliares domésticas. El obispo quería que la veintena de religiosos que fueran a su colegio se dedicasen enteramente a la predicación y la confesión, sin comprender que para que ello se pudiera realizar de la mejor manera posible, era necesario que una serie de personas se encargaran de asuntos más terrenales, como el cuidado de los aposentos, la compra y preparación de comidas, la portería... Finalmente le convencieron de que era lo mejor y que incluso debía aumentar la dotación de 500 a 1.000 ducados porque lo que había dado al principio sólo permitía dar cobijo a una docena de jesuitas. ${ }^{65}$ Junto a estos casos en los que se pone de manifiesto el comportamiento interesado del obispo y la prudencia con la que tuvieron que manejarse los jesuitas en su trato, contemplamos un tercer acontecimiento, que es el que más interesa para el objetivo de estas páginas, esto es, la solicitud de cambio de provincia de adscripción, de Aragón a Castilla y posteriormente, a Toledo. ${ }^{66}$ Puede suponerse que en este punto tuvo mucho que ver la estrecha relación que mantenía Almeyda con el padre Barma, tal y como se ha dicho. A lo largo de las negociaciones para la fundación murciana, el padre Barma fue el jesuita con el que estuvo más en contacto el obispo, al que intentó tener siempre en su entorno cercano, incluso cuando fue nombrado provincial de Aragón en 1558. Su muerte en el año 1560 trastocaría en cierta manera los planes del obispo, que no tardó en pedir el cambio de

64 "Carta de Francisco de Borja a Ignacio de Loyola, de Simancas a 30 de julio de 1555", en MBorgia: III, 235; "Carta de Francisco de Borja a Ignacio de Loyola, de Simancas a 23 de agosto de 1555", en MBorgia: III, 237.

65 "Carta de Antonio de Cordeses a Borja de Murcia a 20 de agosto de 1560", en MBorgia: VII, 133.

66 "Carta de Polanco a Nadal de Roma a 20 de enero de 1561", en MNadal: I, 372-373 y "Carta de Nadal al padre Diego Laínez, de Toledo a 10 de marzo de 1561", en MNadal: I, 416; "Carta de Antonio de Cordeses a Borja de Murcia a 20 de agosto de 1560", en E. García Hernán (ed.) 2009. Monumenta Borgia VII (15501566): 134-135. Valencia-Roma: Institutum Historicum Societatis lesu, Generalitat Valenciana; y "Carta de Alfonso de Polanco a Francisco de Borja de Roma a 15 de enero de 1561", en Ibidem, 139. Se hará referencia a esta obra, como en casos similares, como MBorgia VII. 
provincia, no sólo para el colegio murciano, sino también para toda su diócesis. Según se desprende de la correspondencia, Almeyda no parecía tener buenas relaciones con los jesuitas aragoneses, especialmente con los catalanes y los valencianos, por razones idiomáticas y, en consecuencia, de comportamiento. ${ }^{67}$ Así lo refería el padre Antonio Cordeses, que medió en el asunto:

"El Sr. Obispo ha representado algunas veces sus deseos en que este colegio se quitase de la provincia de Aragón y se pasase a la de Castilla y la de Andalucía, y cierto que aquí juzgamos que sería conveniente porque la gente de esta tierra no es muy aficionada a valencianos ni catalanes, ni en las condiciones y lengua convienen entre sí, por donde tenemos por cierto que haría más aquí un sujeto mediano castellano que uno bueno valenciano no catalán, ultra de lo cual estar este colegio en la provincia de Aragón es preternatural, porque en todas las otras religiones que están, Murcia es de la provincia de la Andalucía". ${ }^{68}$

El caso del padre Barma era particular, puesto que él era castellano: había nacido en Alcalá de Henares en 1524 y había pasado gran parte de su vida en territorio meseteño, graduándose como Maestro en Artes en la Universidad Complutense, realizando el noviciado en esa misma ciudad en 1549, siendo lector de teología en el colegio franciscano de Cuenca y realizando la profesión de votos definitiva en Valladolid en 1556, antes de marchar a Levante, donde ocupó diversos cargos en la recién fundada provincia de Aragón, cuando intervino en el desarrollo de los colegios de Gandía y Valencia, amén del que estamos haciendo referencia en estas líneas. ${ }^{69}$ Su muerte dejaba al obispo sin su interlocutor preferido, quedando en una situación poco propicia para que sus peticiones siguieran siendo atendidas. También hay que tener en cuenta que si los jesuitas de su diócesis dependían de la provincia castellana, él podría velar mejor por sus intereses cuando acudiera a la Corte (madrileña), e incluso hacer presión a través de ella. Esta idea coge fuerza si tenemos en cuenta que al poco tiempo de que esto se produjera, tuvo lugar la segunda reestructuración de las provincias españolas, quedando enmarcada la diócesis de Cartagena en la circunscripción toledana.

67 "Carta de Diego Laínez a Borja, de Roma a 13 de agosto de 1560", en MBorgia: III, 626-627.

${ }^{68}$ MBorgia: VII, 134-135.

${ }^{69}$ Medina, F. de B. 2001. "Juan Bautista de Barma”, en Ch. E. O’Neill y J. Ma Domínguez (dirs.), Diccionario Histórico de la Compañía de Jesús. Biográficotemático: I, 346. Madrid-Roma. 
En fin, que providencialmente la Provincia de Toledo se extiende hacia el Levante, saliendo al mar por el Mediterráneo, por Cartagena, lo cual, al fin y al cabo, era muy conveniente, máxime por facilitar su comunicación con Italia; aunque mucho más tarde, cuando la expulsión de 1767 no fue, precisamente, una ventaja.

No obstante, y como punto de llegada, no vendrá mal reproducir la descripción "definitiva" de la provincia toledana, realizada a fines del XVII o principios del XVIII por el archimencionado Bartolomé de Alcázar, cuando, por cierto, se estaban finiquitando las obras de la Iglesia y de la Casa Profesa de la ciudad de Toledo. También nos servirá de resúmen y colofón a lo expuesto. Es la siguiente:

\section{"Corografía de la Provincia de Toledo"}

La Provincia de Toledo de la Compañía de Jesús está en el corazón de España, ceñida hacia los cuatro puntos cardinales de las otras cuatro provincias, que en estos reinos tiene mi sagrada religión: conviene a saber, confina al oriente con la Provincia de Aragón; al Norte con la de Castilla; al Poniente, parte con la Provincia de Andalucía, y con la de Portugal; y al Mediodía con la misma de Andalucía; y con el Mar Mediterráneo.

Comprehende en lo temporal y político los Reinos de Toledo y de Murcia, las provincias de la Mancha, Cuenca, Alcarria y Extremadura, y el señorío de Molina, que llaman de Aragón. Tiene cinco ciudades de voto en cortes, que son: Toledo, Madrid (cabeza hoy de los reinos de España), Murcia, Guadalajara y Cuenca. Contiene los ducados de Alburquerque, de Béjar, de Escalona, de Feria (en parte), del Infantado, de Maqueda, de Medinaceli, de Pastrana, y de Uceda; los marquesados de Almazán, de Berlanga, de Cañete, de Cogolludo, de Coria, de Espinardo, de Leganés, de Molina, de Mondéjar, de Montes Claros, de Moya, de las Navas, de Villena, y otros; los Condados de Buendía, de Casarrubios, de Chinchón, de Cifuentes, de Fuensalida, de Medellín, de Orgaz, de Oropesa, de Pliego, de Santisteban, de Tendilla, y otros.

En lo Eclesiástico comprehende el arzobispado de Toledo (primado de las Españas) y los obispados de Cuenca, Sigüenza, Plasencia, Cartagena, Badajoz, Coria, y parte de los de Ávila y Segovia, de Montes acá. Contiene también casi todos los distritos de las cuatro órdenes militares como son: en la de Santiago, el priorato de Uclés, mucha parte del de León, las vicarías de Caravaca, Segura y otras, con grande número de encomiendas; en la de Calatrava, todo el Campo que llaman de Calatrava, el gobierno de Almagro y otros; en la de Alcántara, 
esta [misma] villa (cabeza de la orden), con muchas encomiendas en la Extremadura; y en la de San Juan, el Gran Priorato de Castilla. Hay cuatro Tribunales del Santo Oficio de la Inquisición: en Toledo, Murcia, Cuenca y Llerena, que dimanan del Consejo Supremo de la Santa y General Inquisición, el cual tiene su residencia en Madrid, como todos los demás consejos supremos de la Monarquía de España.

Tiene pues la Religión de la Compañía de Jesús en estos reinos y provincias, adjudicados a la que se llama hoy Provincia de Toledo varias casas, colegios, residencias, seminarios, convictorios y misiones que son los siguientes: en esta Corte de Madrid hay Casa Profesa, Casa de Probación o Noviciado, un Colegio Imperial y dos Seminarios, el uno de la Nación Inglesa, y el otro de la Escocesa; en Toledo hay una Casa Profesa y un Colegio; en Alcalá de Henares hay un Colegio, el Máximo de la Provincia y el más antiguo de las de España en las coronas de Castilla y Aragón; hay colegios también en las ciudades de Murcia, Cuenca, Plasencia, Badajoz, Huete, Alcaraz, Guadalajara y Llerena, y en las villas de Ocaña, Talavera, Oropesa, Belmonte, Caravaca, Almonacid de Zorita, Segura de la Sierra, San Clemente y Almagro; hay Casa de Noviciado en Villarejo de Fuentes; están comenzados tres colegios, el uno en la villa de Daimiel, el otro en la ciudad de Cartagena, y el tercero en la villa de Cáceres; hay residencias, una en Navalcarnero (que fue colegio en sus principios), otra en Jesús del Monte y ambas pertenecen al Colegio de Alcalá; una en Arganda, que es de el Colegio Imperial, y una en Esquivias, que es del Noviciado de Madrid; sin contar otras menores, que no tienen mas que uno o dos sujetos, cuales son Molina y el Rahal del Colegio de Murcia, Casasbuenas del de Toledo, la Aldea del de San Clemente, Santa María de la Casa de Villarejo, la Magdalena del Colegio de Plasencia y Villanueva de los Infantes; hay asimismo varios colegiosseminarios y convictorios, que están a cargo de la Compañía en esta Provincia, cuales son el Colegio-Seminario de la Anunciata en la ciudad de Murcia, el Colegio-Seminario de San Bernardo en Oropesa, el Convictorio del Beato Luis Gonzaga en Ocaña y el Convictorio de San Francisco de Borja en Plasencia. Están también a cargo de la misma Provincia de Toledo algunas misiones anuales, cuales son las de los Montes de Toledo, que pertenece al colegio de aquella ciudad, la del Marquesado de las Navas que toca al Noviciado de Madrid, la de la villa de Buendía que es del Colegio de Huete, la de la villa de Casa Tejada que es del Colegio de Oropesa, y otras dos en las villas de Valdemoro y de Puertollano. 
Las casas y colegios de España a los principios se comprehendieron en una provincia, después en dos, luego en tres y últimamente en cuatro, con la planta en que hasta hoy se mantiene". ${ }^{70}$

Así, la Provincia Toledana sería estratégica por su centralidad en el panorama ibérico. Una historia que, con altos y bajos, fue una pujante realidad religioso-institucional, hasta que, después de una breve vuelta a Castilla en 2004 , en estos primeros años del siglo XXI (con vistas al 2014) todas las provincias jesuíticas se integren en una sola "Provincia de España", tal como fue al principio de los principios, ad maiorem Dei gloria.

\section{BIBLIOGRAFÍA}

Alcázar, B. de. 1710. Chrono-Historia de la Provincia de Toledo de la Compañía de Jesús en Madrid, por juan Garcia Infançon, impresor de la Santa Cruzada.

Antonio, F. 1604. Historia de la Provincia de Toledo, 2 vols.

Aranda Pérez, F. J. 2009. "¿Sangre o mérito? Noblezas, virtudes cívicas, virtudes religiosas en la Monarquía Hispánica de los Felipes”, en M. Rivero Rodríguez (coord.), Nobleza hispana, Nobleza cristiana: la Orden de San Juan: 832-862. Madrid.

Aranda Pérez, F. J. y Morales Sánchez-Tembleque, M. 2010. "El régimen señorial de los Prioratos de San Juan en la Mancha en el primer tercio del siglo XVII", en F. Ruiz Gómez y J. M. Molero García (eds.), La Orden de San Juan en tiempos del Quijote: 207-233. Cuenca.

Aranda Pérez, F. J., Martín López, D. 2012. "Pensamiento político more Societatis lesu: entre la teología moral y la razón de Estado", en J. Martínez Millán, H. Pizarro Llorente, E. Jiménez Pablo (Coords.), Los Jesuitas. Religión, política y educación (siglos XVI-XVIII): 1.309-1.338. Madrid.

Aranda Pérez, F. J. 2013. "El influjo complutense, de Cisneros y Fonseca a Carranza", en I. J. García Pinilla (Coord.), Disidencia religiosa en Castilla la Nueva en el siglo XVI: 29-57. Toledo.

Arnaldos Pérez, M. 1973. Los jesuitas en el reino de Murcia (apuntes históricos) Madrid.

${ }^{70}$ Alcázar, B. de. 1710: I, 1-3. 
Astrain, A. 1902-1925. Historia de la Compañía de Jesús en la Asistencia de España Madrid, 7 vols.

Ayguals de Izco, D.W. 1848. Los jesuitas o análisis documentado de la Compañía de Jesús por las autoridades más competentes desde su fundación en el año 1540 Madrid, 6 vols.

Epistolae P. Hieronymi Nadal ab anno 1546 ad 1577 [Monumenta Nadal], 1898-1905, Madrid, 4 vols.

Fernández Collado, A. 1996. Concilios toledanos postridentinos. Estudio y edición Toledo. Valencia.

García Hernán, E. 1999. Francisco de Borja, Grande de España

García Hernán, E. y Ryan, M. P. (eds.) 2011. Francisco de Borja y su tiempo. Política, religión y cultura en la Edad Moderna. Valencia-Roma.

García Hernán, E. 2000. La acción diplomática de Francisco de Borja al servicio del Pontificado, 1571-1572 Valencia.

García Hernán, E. (ed.) 2003. Monumenta Borgia VI (1478-1551). Valencia-Roma: Institutum Historicum Societatis lesu, Generalitat Valenciana.

García Hernán, E. (ed.) 2009. Monumenta Borgia VII (1550-1566). Valencia-Roma: Institutum Historicum Societatis lesu, Generalitat Valenciana.

Hernández Franco, J. 2011. Sangre limpia, sangre española. El debate de los estatutos de limpieza (siglos XV-XVII) Madrid.

Higuera, Jerónimo Roman de la. 1600. Historia del colegio de Plasencia de la Compañía de Jesús, manuscrito inédito del Archivo Histórico Provincial de Castilla de la Compañía de Jesús (Alcalá de Henares).

Higuera, Jerónimo Román de la. Historia eclesiástica de la imperial ciudad de Toledo, manuscrito localizado en BNE, Mss/1293.

lanuzzi, I. 2000. "Mentalidad inquisitorial y jesuitas: el enfrentamiento entre el cardenal Silíceo y la Compañía de Jesús", Cuadernos de Historia Moderna, 24: 167-181. 
Játiva Miralles, M. V. 2008. La biblioteca del colegio de San Esteban de los jesuitas de Murcia Murcia.

Jiménez Pablo, E. 2011. La lucha por la identidad en la Compañía de Jesús: entre el servicio a Roma y el influjo de la monarquía hispana (15731643) tesis doctoral inédita leída en la Universidad Autónoma de Madrid, Facultad de Filosofía y Letras, Departamento de Historia Moderna, el 29 de septiembre de 2011.

Lop Sebastiá. M. (ed.) 2011. Las pláticas del P. Jerónimo Nadal Bilbao.

López-Salazar Pérez, J. 2009. "El Gran Priorato de San Juan: señorío y conflictividad en la Edad Moderna", en F. Ruiz Gómez y J. M. Molero García (eds.), La Orden de San Juan, entre el Mediterráneo y la Mancha: 219-324. Cuenca.

López-Salazar Pérez, J. (coord.) 2000. Las Órdenes Militares en la Península Ibérica, vol. II: Edad Moderna, Cuenca.

Lozano Navarro, J. J. 2005. La Compañía de Jesús y el Poder en la España de los Austrias Madrid.

Marías, F. 2007. El Hospital de Tavera de Toledo Sevilla.

Marías, F. 1983-1986. La arquitectura del Renacimiento en Toledo, 1541-1631 Toledo.

Martín López, D. 2014. Orígenes y evolución de la Universidad de Toledo (1485-1625), Toledo, Cortes de Castilla-La Mancha, Universidad de Castilla-la Mancha.

Martín López, D. 2011. "La provincia jesuítica de Toledo en tiempos de Francisco de Borja (1551-1572)", en E. García Hernán y M. P. Ryan (eds.), Francisco de Borja y su tiempo (1510-1572). Política, religión y cultura en la Edad Moderna: 481-522. Valencia-Roma.

Martínez Millán, J. 2009. "Nobleza hispana, nobleza cristiana: los estatutos de limpieza de sangre", en M. Rivero Rodríguez (coord.), Nobleza hispana, Nobleza cristiana: la Orden de San Juan: 677-758. Madrid.

Martínez Millán, J. 2003. "La crisis del "partido castellano» y la transformación de la Monarquía Hispana en el cambio de reinado de Felipe II a Felipe III", Cuadernos de Historia Moderna Anejo II: 11-38. 
Martínez Millán, J. 1998. "Transformación y crisis de la Compañía de Jesús (1578-1594)" en F. Rurale (a cura di): I Religiosi a Corte. Teologia, Politica e Diplomazia in Antico Regime: 101-129. Roma, Bulzoni editore.

Medina, F. de B. 2001. "Juan Bautista de Barma”, en Ch. E. O'Neill y J. Ma Domínguez (dirs.), Diccionario Histórico de la Compañía de Jesús. Biográfico-temático: I, 346. Madrid-Roma.

Monumenta Ignatiana ex autographis vel ex antiquioribus exemplis collecta, 1903-1911. Madrid, 12 vols.

Monzón, B. de. 1658. Menologio de Ylustres por todo el orbe y famosos hijos de San Ygnazio Patriarca y fundador de la Compañía de Jesús en ciento y diez y ocho años de su fundación hasta el presente de 1658. Manuscrito localizado en BNE, Mss/12861.

Nadal, J. 1594. Adnotationes et Meditationes in Evangelia: Quae in sacrosancto missae sacrificio toto anno leguntur, cum evangeliorum concordantia, historiae integritati sufficienti Amberes, Martinus Nutius.

Nadal, J. 1593. Evangelicae Historiae Imagines: Ex ordine Euangeliorum, quae toto anno in Missae Sacrificio recitantur, In ordinem temporis vitae Christi digestae Amberes.

Nadal Cañellas, J. 2007. Jerónimo Nadal. Vida e influjo Bilbao.

Nieremberg, J.E. 1644. Firmamento Religioso de lúcidos astros en algunos claros varones de la Compañía de Jesús en Madrid, por María de Quiñones.

Nieremberg, J.E. 1666. Varones Ilustres en santidad, letras y celo de las almas de la Compañía de Jesús en Madrid, por loseph Fernández de Buendía.

Palomo, F. 2004. "De algunas cosas que sucedieron estando en misión: espiritualidad y escritura misionera en la Península Ibérica (siglos XVI y XVII)", en A Companhia de Jesus da Península Ibérica nos séculos XVI a XVIII: espiritualidade e cultura: I, 119-150. Oporto.

Palomo, F. 2007. "Limosnas impresas. Escritos e imágenes en las prácticas misioneras de interior en la Península Ibérica (siglos XVI-XVIII)", Manuscrits. Revista d'Història Moderna 25: 239-265. 
Palomo, F. 2003. Fazer dos campos escolas excelentes: os Jesuítas de Évora e as missôes do interior em Portugal (1551-1630) Lisboa.

Patris Petri de Ribadeneyra, Societatis Jesu sacerdotis, Confessiones, epistolae aliaque scripta inedita, ex autographia, antiquissimis apographis et regestis deprompta [Monumenta Ribadeneyra], Madrid, 1920-1923, 2 vols.

Peña Gómez, Ma P. de la. 1991. "Estudio arquitectónico del colegio jesuítico de Plasencia". Norba-arte 11: 39-50.

Pereda de la Reguera, M. 1950. Bartolomé de Bustamante Santander.

Pizarro Llorente, H. 2004. Un gran patrón en la corte de Felipe II. Don Gaspar de Quiroga Madrid.

Polanco, J. A. de. 1894-1898. Vita Ignatii Loiolae et rerum Societatis Jesu Madrid, 6 vols.

Ribadeneyra, P. de. 1611. Historia de la Compañía de Jesús de las Provincias de España y parte de las del Piru y Nueva España y Philippinas. Manuscrito localizado en ARSI, Hispania-94.

Ribadeneyra, P. de. 1594. Vida del P. M. Diego Laynez en Madrid, por Pedro Madrigal.

Ribadeneyra, P. de. 1594. Vida del P. Francisco de Borja en Madrid, por Pedro Madrigal.

Rodríguez de Campomanes, V. P. 1977. Dictamen fiscal de expulsión de los jesuitas de España (1766-1767) Madrid: edición y estudio de J. Cejudo y T. Egido.

Rodríguez Gutiérrez de Ceballos, A. 1967. Bartolomé de Bustamante y los orígenes de la arquitectura jesuítica en España Roma.

Sanctus Franciscus Borgia, quartus Gandiae dux et Societatis Jesu Praepositus Generalis tertius [Monumenta Borgia], 1894-1911, Madrid, 5 vols.

Santalla, F. 1681. El grande a lo divino S. Francisco de Borja..., s.I., s.n.

Ser Pérez, F. del. 1998. "La provincia jesuítica de Castilla en el Archivum Romanum Societatis lesu". Cuadernos de Historia Moderna 20: 167188. 
Sicroff, A. A. 1985. Los estatutos de limpieza de sangre: controversias entre los siglos XV y XVII Madrid.

Vaquero Serrano, M. C. 2006. El libro de los maestrescuelas. Cancelarios y patronos de la Universidad de Toledo en el siglo XVI Toledo.

Altorrelieve votivo de la Imposición de la Casulla a San Ildefonso, en la fachada de la Iglesia de los Jesuitas, cabe a su Casa Profesa, en Toledo (principios siglo XVIII) (F. AA.)

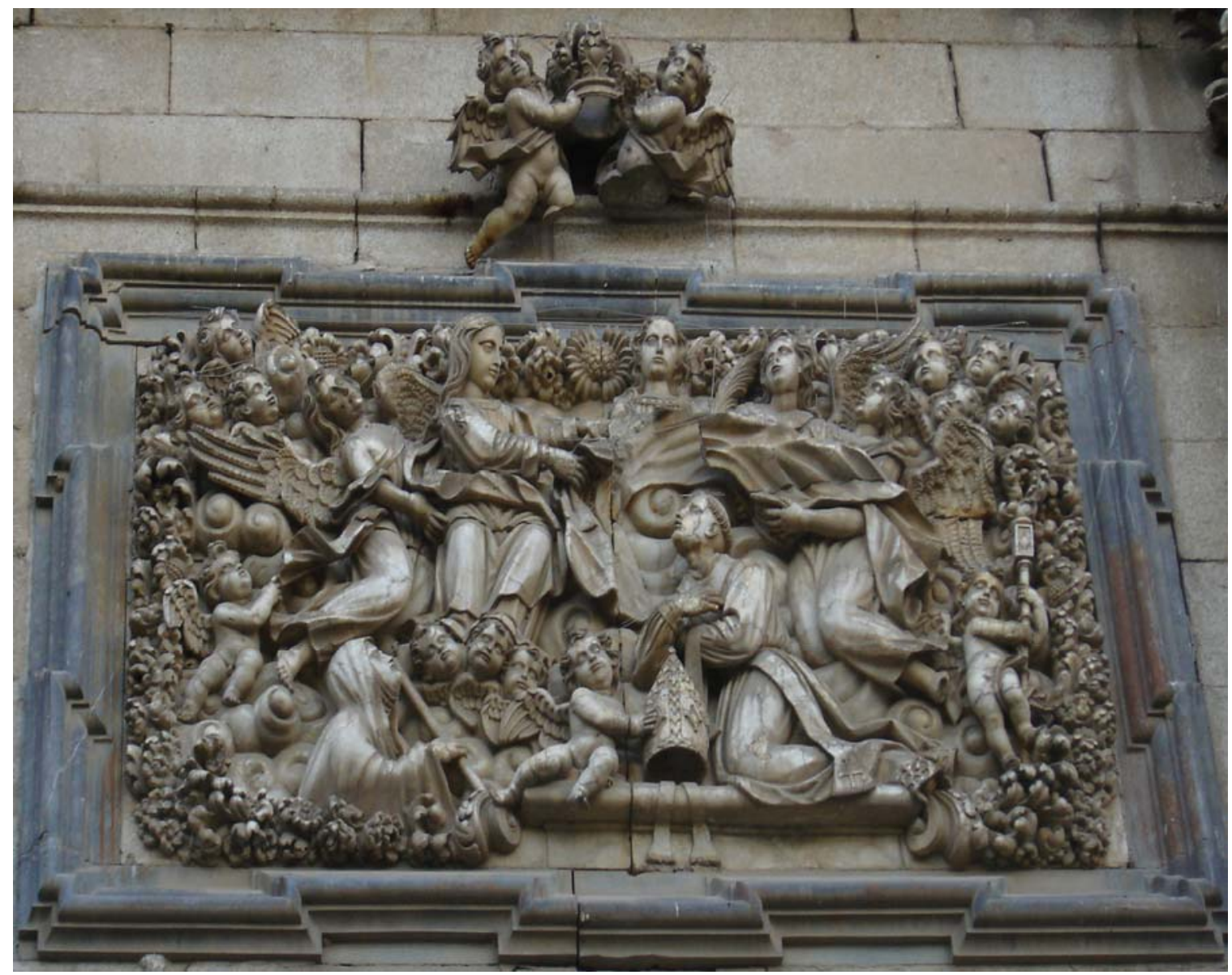


Escudo Jesuítico de la Portada de la Vida de Diego Laínez de Pedro Ribadeneyra, Madrid 1594 (Ejemplar de la Biblioteca de Castilla-La Mancha) (F. AA.)

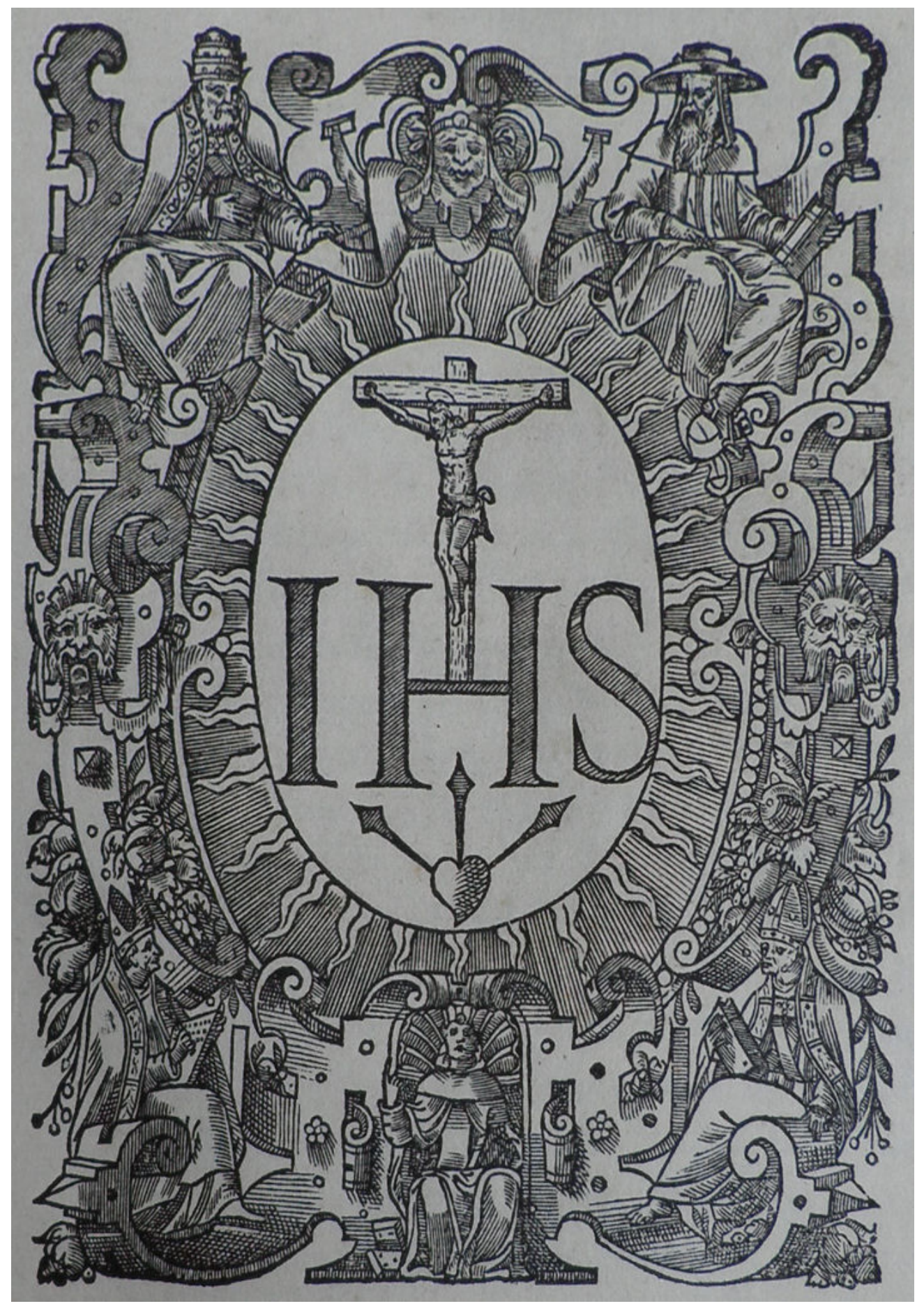

